Research Article

\title{
Functional Modification Effect of Epoxy Oligomers on the Structure and Properties of Epoxy Hydroxyurethane Polymers
}

\author{
Victor Stroganov, ${ }^{1}$ Oleg Stoyanov, ${ }^{2}$ Ilya Stroganov, ${ }^{2}$ and Eduard Kraus $\mathbb{1 D}^{3}$ \\ ${ }^{1}$ Kazan State University of Architecture and Engineering, Zelenaya 1, 420043 Kazan, Russia \\ ${ }^{2}$ Kazan National Research Technology University, Karl Marx 68, 420015 Kazan, Russia \\ ${ }^{3}$ SKZ-German Plastic Center, Friedrich-Bergius-Ring 22, 97076 Wuerzburg, Germany \\ Correspondence should be addressed to Eduard Kraus; e.kraus@skz.de
}

Received 15 March 2018; Revised 9 May 2018; Accepted 5 June 2018; Published 9 August 2018

Academic Editor: Ana María Díez-Pascual

Copyright ( 2018 Victor Stroganov et al. This is an open access article distributed under the Creative Commons Attribution License, which permits unrestricted use, distribution, and reproduction in any medium, provided the original work is properly cited.

\begin{abstract}
We introduce different ways to solve the actual fragility problem of the epoxy-amine polymers by curing epoxidian oligomers with aliphatic amines without additional heat input. The pathways are the oligomer-oligomeric modification of epoxy resins-epoxy oligomers (EO), with their conversion to oligoethercyclocarbonates (OECC) by carbonization with carbon dioxide. The cocuring of these oligomers as a result of aminolysis competing reactions is "epoxide-amine" (forming a network polymer) and "cyclocarbonate-amine" (forming the linear hydroxyurethane, extending the internodal chains). Formation of internal and intermolecular hydrogen bonds was established on hydroxycarbonates (HA) and linear polyhydroxyurethanes (PHU) model compounds by IR and NMR spectroscopy. The results of the hydrogen bond system formation processes explain the change in the relaxation and physicomechanical properties of hard polymers modified by the epoxy-amine compositions (OECC), containing aromatic and aliphatic links. This paper presents a possible OECC modificator, the optimal EO:OECC ratio and its influence on the cross-link frequency, the polarity, the fragment and chain flexibilities and, as a consequence, the possible stiffness regulation for selected epoxy polymers. Thus, the causes of the increase in deformation-strength and adhesion characteristics were established by a factor of 1.5 to 3.0 due to an increase in cohesive strength (as a result of the combined network operation with covalent and physical bonds), as well as reduction of residual stresses (by adding the aliphatic fragments as additional relaxants), and reducing the defectiveness of the boundary layers (polymer-substrate).
\end{abstract}

\section{Introduction}

Materials based on epoxy oligomers such as epoxy polymers and composites with epoxy polymeric matrix possess a unique complex of valuable technological and operational properties. Characteristics like high adhesion to most materials, low shrinkage during curing, high strength, low creep under load, good chemical, biological stability, and electrical insulation ensure their successful and effective use in various applications and industries. The production development and the use of epoxy-based compositions and materials expand very fast. The new types of resin-oligomers, hardeners, active diluents, and compositions are emerging. These trends are undoubtedly associated with increasing interest in the physicochemistry of epoxy polymers, their structural organization, and connection with properties, which is reflected in monographic literature and reviews, published in collections and journals. Accordingly, the need for development of new composite materials is also very high. Relevant in this context are the novel possibilities of modifying epoxy polymers [1-9].

\section{Theory}

A feature of high molecular substances is their diverse nature and complex structure, which can not be described in one way. Conventionally, four interrelated structural levels can be distinguished: molecular, topological, supramolecular, and dispersive colloidal [10-18]. The main reason for this interrelation is the influence of the chemical structure of grid 
fragments (atoms and atomic groups) on the realizing possibility for each known type of the intermolecular interactions (physical bonds grid). In the chemical structure of polymers, the elemental composition of structural units, the type and position of functional groups, and the configuration and conformation of polymer chains characterize their molecular level.

The topological structure characterizes the cohesion and branching in a reticular polymer, which can be represented as a macroscopic molecule combining a system of cyclic structures with a system of different internode chains distributed throughout the volume. Such a molecule can be represented as an infinite graph [16]. Within the framework of this representations, the concept of nodes $\left(\gamma_{\mathrm{c}}\right)$, chains $\left(n_{\mathrm{c}}\right)$ or the average static mass of the chain interstitial segment $\left(M_{\mathrm{c}}\right)$ is the main characteristics of the topological structure, under the assumption of ideal networks (tetrahedral, cubic, etc.). The presence of topological defects (grid irregularity, chain inefficiency, closed loops, and unbound sol fraction) is a characteristic difference of real structures in reticular polymers from ideal ones. It has been shown that for epoxy-amine polymers, the main types of chemical defects are "free ends," and topological ones are chemical assemblies that have different connectivity with the wire mesh [19]. The abovementioned topological elements of the structure (I-V) can be conditionally classified: 3 - and 4related nodes (I, II) forming a grid; 2-connected nodes (III) of linear fragments, 1-bound (IV) nodes of free ends, and sol-fraction connections (V). These defects cause a decrease of degree of conversion for the reactive groups to the values of $\alpha_{\lim }^{\text {top }}=92-93 \%$ (topological limit) at theoretical limit values $\alpha_{\mathrm{lim}}^{\text {theor }}=97-98 \%$ for three-dimensional grid models. It is generally accepted that these characteristics determine the basic properties of network polymers [3, 20, 21].

The supramolecular structure is determined by the nature of intermolecular interactions of chemical structural elements, lateral active chains, and the degree of ordering in their mutual arrangement. The nature of the intermolecular interaction in epoxy polymers is determined by the presence of polar atoms, groupings, and their interaction in the topological grid fragments (I-IV). The following types of intermolecular interactions are distinguished in polymers [22]: dispersion, inductive, dipole, and hydrogen bonds. These named interactions form a labile spatial grid (with a stable network of covalent bonds). In particular, in densely cross-linked epoxy polymers, the physical grid of hydrogen bonds exceeds the concentration of chemical assemblies by $2-4$ times, reaching densities up to $4 \times 10^{21} 1 / \mathrm{cm}^{3}[23,24]$. The role of the hydrogen bond between the oxygen atoms of the oxirane ring and the hydrogen for hydrogen bonding of the hydroxyl group during the aminolysis of epoxy compounds has been considered in a number of works. The results of calculating the distribution of hydrogen-bonded groups and the types of $\mathrm{H}$-bonds are considered in detail in [25]. Based on the literature data, the authors believe that the defining influence on the topological structure formation of the network polymers has the formation of an intramolecular hydrogen bond between the epoxy and hydroxyl groups of the following type [26]:

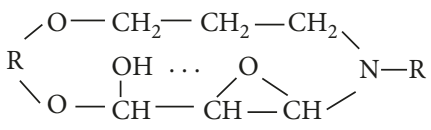

Formation of an intracellular bond system with hydrogen bonds leads to the strengthening and ordering the spatial network of cured epoxy oligomers [27]. Pochan et al. [28] associate relatively high values of crystallization temperature $T_{c}$ and destructive loading of polymers with intermolecular hydrogen bonds formed by hydroxyl groups:

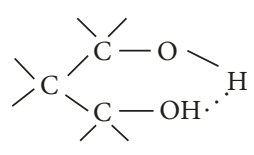

Despite the contradictory nature of these researchers, the prevailing view is that the influence of intermolecular interactions is multifaceted. This approach explains and causes wide possibilities for modifying the properties of epoxyamine network polymers, also due to covalent and physical bonds.

The presented data make possible the representation of the epoxy polymer structure as a superposition of two grids: a covalent bonds network characterized by inhomogeneity at the molecular and topological levels and a thermofluctuation physical bonds grid caused by the realization of all possible types of intermolecular interactions groups and grid fragment atoms. The presented model assumes the possibility of regulating the molecular mobility of network polymers due to a change in the chemical structure (the nature of the node, internodal fragments and their kinetic flexibility, polarity of groups, etc.). Numerous studies on the effect of the chemical structure and properties of epoxy polymers show that changing the initial oligomers nature, hardeners, and their ratio can affect the structure and physicomechanical properties of epoxy polymers and materials based on them.

By analyzing the properties of epoxy polymeric material complexes, the "brittleness" of epoxide-amine polymers obtained with amine curing without additional heat input (such compositions are often used in practice in various technologies) should be noted as a considerable disadvantage. This drawback is due to an inhibition of the aminolysis reaction, a decrease in the degree of reactive group conversion $\alpha_{\mathrm{lim}}^{\text {top }}$, and as a result, a significant reduction in the level of cohesive $\left(\sigma_{\mathrm{c}}, \varepsilon_{\mathrm{c}}\right)$ and adhesive strength $\left(\sigma_{\mathrm{a}}, \tau_{\mathrm{a}}\right)$. It is known that aliphatic chains increase the flexibility of densely cross-linked epoxy-amine polymers. Their conformational set and kinetic flexibility are practically independent from location of these chains (e.g., in the oligomer molecule, in the linear polymer chain, or in the mesh polymer). This provision is very important since it indicates the fundamental influence of the initial molecule structure of oligomers and hardeners on the cured polymer properties. Among the main factors regulating the molecular level of the structure, the reactivity of the initial components (the presence of functional groups in the oligomer, the hardener, 
and their potential activity in various types of reactions), the temperature-time regimes for process realization, the mechanisms of polyreactions themselves, (polymerization, polycondensation, and polyaddition), and so on were presented [29].

Proceeding from the theoretical propositions above, to solve the epoxy-amine polymers' "stiffness" problems, following purposes of this article have been formulated:

(i) The analysis of theoretical bases for the formation of epoxy-amine polymer networks.

(ii) The process study of epoxy oligomers functional modification with different chemical structures and their carbonization into cyclic carbonates.

(iii) The properties of epoxy hydroxyurethane polymers formed as a result of the competition of aminolysis oligomers reactions (EO and OECC) at their simultaneously curing.

It can be assumed that a partial change in the network structure of epoxy-amine polymers (due to the introduction of linear hydroxyurethane fragments obtained on the basis of OETC with different structures containing highly polar hydroxyurethane groups) will provide the opportunity to regulate intermolecular interactions (a physical bonds network) and the molecular mobility of modified polymers in vitreous and elastomeric states. Such a functional modification will make it possible to purposefully apply the relaxation and physicomechanical properties of epoxy-amine polymers and understand the reasons for their "rigidity."

\section{Materials and Methods}

3.1. Materials. The epoxy oligomer ED-20 was used in the compositions studied. ED-20 contains $21.5 \%$ epoxy, with molecular weight 400 to $450 \mathrm{~g} / \mathrm{mol}$ and oligomerization degree $n=0.2$. Following OECC modifiers containing fragments differing in structural rigidity have been used: aromatic (based on ED-20), aliphatic with methyl, chloromethyl, and cyclic fragments in the side chain, and an amine hardener, the diethylenetriamine (DETA). OECC were obtained by the interaction of various epoxy oligomers with $\mathrm{CO}_{2}$. The structure can be represented by the following general formula:<smiles>[R20]OCC1COC(=O)C(COC(=O)O)[R20]OCC(O)C1</smiles>

where $R$ the is residues of alcohol, phenol, or carboxylic acid and $n$ is the degree of oligomerization. The characteristics of the OECC are shown in Table 1.

It has been established that relatively close reactivity values are observed in the reactions of $\mathrm{CO}_{2}$ with glycidyl ethers of phenols, alcohols, and acids. Consequently, the conditions for the synthesis of cyclic carbonates based on glycidyl ethers [30] have been determined: the ratio of reagents, temperature, type and amount of catalyst, mass exchange conditions, and others.
3.2. Synthesis of the OECC. The epoxy oligomers (1 mol) were placed in a reactor equipped with a stirring device, a heating element, and a coil to cool the reaction mass. The mixture was heated to the prescribed temperature of 120 to $140^{\circ} \mathrm{C}$, the required amount of catalyst was introduced $C_{\mathrm{c}} \approx 0.025 \mathrm{~mol} / \mathrm{kg}$, and after $2 \mathrm{~min}$ a sample was taken to determine the epoxy groups initial concentration. Subsequently the reactor was sealed and carbon dioxide was added $\left(V_{\mathrm{CO}_{2}}=4.5 \mathrm{l} / \mathrm{h}\right.$ with stirring $n=300 \mathrm{rpm}$ and $P=0.3 \mathrm{MPa}$ ). The reaction was monitored by changing the concentration of the epoxy groups by the sampling method $(1 \mathrm{ml}$ of the reaction mixture was taken, quenched, and analyzed).

Various catalysts for the reaction of epoxide compounds with carbon dioxide can be found in the literature today [31]. Catalytic systems containing halide salts found actually the greatest application among them. The catalytic activity of haloanions increases in the series as follows: $\mathrm{I}>\mathrm{Br}>\mathrm{Cl}$. For alkali metal halides, the catalytic activity increases with increasing cation radius. The localization of the alkali metal accelerates the reaction to a greater extent. Thus, the catalytic system " $\mathrm{KCl}$ and crown ether of dibenzo-18-crown-6" exhibit greater activity (reaction rate constant $K=1.28 \times$ $\left.10^{-2} \mathrm{~kg} \cdot \mathrm{mol}^{-1} \cdot \mathrm{s}^{-1}\right)$ as $\mathrm{KCl}\left(K=9.56 \times 10^{-3} \mathrm{~kg} \cdot \mathrm{mol}^{-1} \cdot \mathrm{s}^{-1}\right)$. It has been established that an increase in the reactor volume does not adversely affect the quality of the cyclocarbonates obtained.

\subsection{Saponification Number Determination of Cyclocarbonate} Groups. The analyzed product between 0.1 and $0.2 \mathrm{~g}$ was weighed $( \pm 0.0002)$ in a $100 \mathrm{ml}$ flask and dissolved in $10 \mathrm{ml}$ of acetone. Subsequently $5 \mathrm{ml}$ of $0.7 \mathrm{M}$ sodium hydroxide solution was poured in. The resulting mixture was heated for 30 minutes in a boiling water bath with a reflux condenser. After that, the flask was lifted, slightly cooled, and disconnected from the refrigerator. $20 \mathrm{ml}$ of distilled water and $10 \mathrm{ml}$ of a $10 \%$ solution of barium chloride (previously neutralized by phenolphthalein) were added to the mixture. The flask was closed with stopper, mixed, and cooled. Excess sodium hydroxide was titrated with $0.1 \mathrm{M}$ hydrochloric acid in the presence of phenolphthalein until the pink color disappeared.

In parallel, a blank test was carried out under the same conditions, but without analyzing the product. The saponification number $(X)$ in of $\mathrm{KOH} / \mathrm{g}$ product was calculated by the formula: $X=\left(V_{0}-V\right) \cdot K \cdot 5.6 / m$, where $V_{0}$ and $V$ are the volumes of the hydrochloric acid solution consumed for titration in the blank test and the sample of the product, respectively. $K$ is the correction factor to $0.1 \mathrm{M} \mathrm{HCl}$ solution. 5.6 is the amount of potassium hydroxide corresponding to exactly $1 \mathrm{ml}$ of $0.1 \mathrm{M} \mathrm{HCl}$ solution, and $M$ is the weight of the sample of the product. For the result analysis, the average of three parallel definitions was taken, which discrepancy was no more than $20 \mathrm{mg} \mathrm{KOH} / \mathrm{g}$ with a confidence level of 0.95 .

3.4. Mass Fraction Determination of Epoxy Groups (Epoxy Number). To determine the residual epoxy number, $1 \mathrm{~g}$ of CC sample was used. The reaction products (OECC) were dissolved in chloroform, and DCC/ED-20 was solved in 


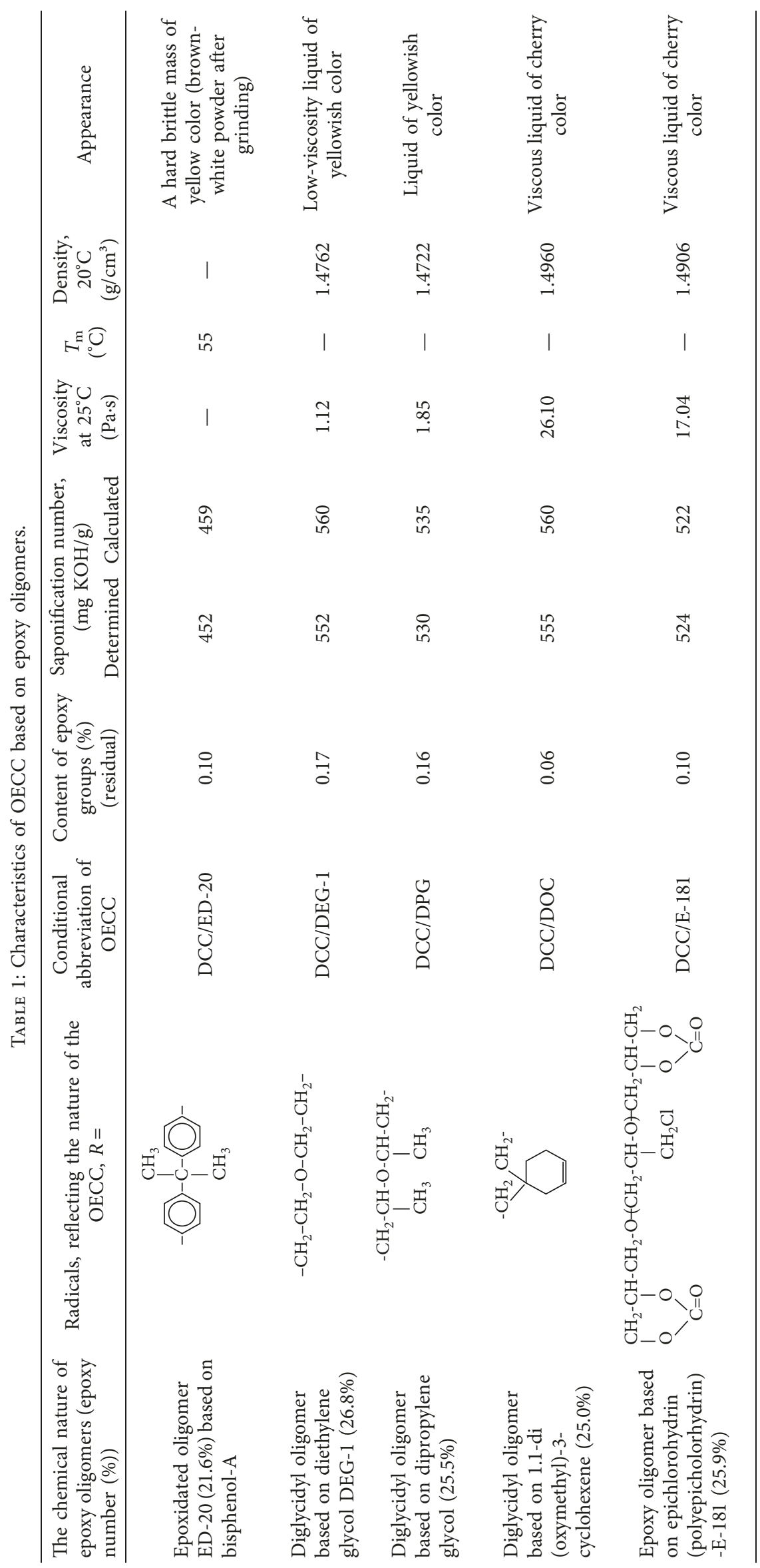


dioxane. The epoxy number determining was carried out according to GOST 12497-78.

3.5. Calculation of Amine Hardener Amount for CCCompositions. The hardener was always taken in a stoichiometric amount under consideration of its interaction with epoxy and cyclocarbonate groups. The amount of hardener $(X)$ per $100 \mathrm{~g}$ of the mixture of oligomers was determined according to the following formula:

$$
X=\alpha \times k_{\mathrm{EO}} \times \mathrm{M}_{\mathrm{EG}}+\beta \times k \mathrm{cc} \times \% \mathrm{CC},
$$

where $\alpha$ and $\beta$ are the mass fractions of oligomers in the mixture, $K_{\mathrm{EO}}$ and $K_{\mathrm{CC}}$ are the stoichiometric coefficients of the hardener with respect to epoxy and cyclocarbonate oligomers, CC is the mass fraction of cyclocarbonate groups, and $M_{\mathrm{EG}}$ is the mass fraction of epoxy groups.

3.6. Strength and Adhesion Properties. For evaluating the mechanical properties, the following values were determined: the tensile strength $\left(\sigma_{\mathrm{p}}\right)$ and the elongation $\left(\varepsilon_{\mathrm{p}}\right)$ at break according to DIN EN ISO 527 and the tensile shear strength of adhesive joints $(\tau)$ in accordance with DIN EN 1465 with uniform separation $\left(\sigma_{\text {p.o }}\right)$ in accordance with ISO 4587. The data of physical and mechanical tests were processed using the software Statgrafica.

3.7. Thermomechanical Analysis (TMA). TMA was carried out under uniaxial compression at stress of $1.5 \mathrm{MPa}$ and a temperature rise rate of $2.5^{\circ} \mathrm{C} / \mathrm{min}$. Samples of cylindrical shape with diameter $10 \mathrm{~mm}$ and height $10 \mathrm{~mm}$ were used. The glass transition temperature $\left(T_{\mathrm{g}}\right)$ and the transition temperature to the high-elastic state $\left(T_{\mathrm{m}}\right)$ were determined by conventional methods (by the tangents intersection).

3.8. Topological Grid Parameters. The most important topological grid parameter is the interstitial chain fragment molecular mass $\left(M_{\mathrm{c}}\right)$. It was determined from Wall's formula [12] that $M_{\mathrm{c}}=3 \cdot \rho \cdot R \cdot T \cdot \varepsilon_{\mathrm{e}} / \sigma$, where $\rho$ is the density of the polymer, $T$ is the absolute temperature, $R$ is the gas constant, $\varepsilon_{\mathrm{e}}$ is the relative deformation in the highly elastic state, and $\sigma=N / S$ is the stress applied to the sample. The effective density of the polymer network nodes $\left(\gamma_{\mathrm{c}}\right)$ was determined from the following relation: $\gamma_{\mathrm{c}}=2 \cdot \rho \cdot N_{0} /\left(3 \cdot M_{\mathrm{c}}\right)$, where $N_{0}$ is the Avogadro number.

3.9. IR Spectroscopy. IR spectra of oligomeric and polymeric systems were recorded on a two-beam Carl Zeiss UR-20 spectrophotometer with the detection range from 400 to $4000 \mathrm{~cm}^{-1}$. The following operating parameters were used: target program nr. 4, scanning speed was $160 \mathrm{~cm}^{-1}$ for normal spectrum, and $32 \mathrm{~cm}^{-1}$ for frequency refinement spectrum. The registration scale was $20 \mathrm{~min} / 100 \mathrm{~cm}^{-1}$. The spectra of the polymer samples were taken in the condensed state in the film with the thickness $\delta=10$ to $20 \mu \mathrm{m}$ between the $\mathrm{KBr}$ plates. At elevated temperatures, a special thermocuvette was used. The solutions spectra were recorded in $\mathrm{KBr}$ and KRS- 5 cuvettes with a thickness of 0.07 to $3.00 \mathrm{~mm}$.
For investigating the curing processes of polymer systems, the cuvette windows were covered with a fluoroplastic film with thickness $\delta=10 \mu \mathrm{m}$. The spectra were recorded in the regions 800 to $1000 \mathrm{~cm}^{-1}$ and 1600 to $1900 \mathrm{~cm}^{-1}$. In these ranges, an uncompensated absorption of the fluoroplastic film could be considered. The fraction of unreacted functional groups (epoxy and cyclocarbonate) was determined by normalizing the optical density of the corresponding band at time of the first measurement $t_{\mathrm{c}}(1 \mathrm{~min}$ after the oligomers were mixed with the curing system).

3.10. Dielectric Loss Method. Measurement of the dielectric parameters was carried out in the frequency range from $10^{3}$ to $10^{6} \mathrm{~Hz}$ and the temperature range from -180 to $+250^{\circ} \mathrm{C}$ on samples in the disk form with a diameter of $50 \mathrm{~mm}$ and a height of 2 and $3 \mathrm{~mm}$. The samples were previously covered with aluminum foil.

3.11. Nuclear Magnetic Resonance Method. Two methods are most effective for research in solids and viscous liquids (oligomers and polymers): pulsed NMR and NMR of wide lines. The first is based on the study of magnetic relaxation at various temperatures, estimated by spin-lattice $\left(T_{1}\right)$ and spin-spin $\left(T_{2}\right)$ relaxation. The second is based on the shape study of the line and its temperature dependence. The study was performed on a laboratory coherent NMR relaxometer at a frequency of $17 \mathrm{MHz}$. The decay curves of the transverse magnetization (DCTM) were recorded by the Carr-Parcell-Meibum-Gil method from the free induction decay [32]. The measurement was carried out under isothermal conditions, as well as with a stepwise temperature rise in the range from 20 to $220^{\circ} \mathrm{C}$ with an isothermal holding time of 15 minutes. The molecular mobility was estimated from the times of transverse spin-spin relaxation $T_{2}$. In the general case, the free induction decay is described by a function as a superposition of several terms:

$$
f(t)=P_{\mathrm{a}} \cdot \exp \left(-\frac{t}{T_{2 \mathrm{a}}}\right)+P_{\mathrm{b}} \cdot\left(-\frac{t}{T_{2 \mathrm{~b}}}\right)+P_{\mathrm{c}} \cdot \exp \left(-\frac{t}{T_{2 \mathrm{c}}}\right),
$$

where $P_{\mathrm{a}}, P_{\mathrm{b}}$, and $P_{\mathrm{c}}$ are the relative proton nuclei fractions that relax with transverse relaxation times $T_{2 \mathrm{a}}, T_{2 \mathrm{~b}}$, and $T_{2 \mathrm{c}}$.

"Phases $a$ " is formed by nuclei with longer relaxation times and "phase $b$ and $c$ " with shorter ones, respectively. The times $T_{2 \mathrm{~b}}$ and $T_{2 \mathrm{c}}$ were determined by successively subtracting the values of the longer relaxation component from the values of the experimental curves. The population of the "phases" (the number of protons entering this "phase") $P_{\mathrm{a}}, P_{\mathrm{b}}$, and $P_{\mathrm{c}}$ was calculated from the contribution to the initial amplitude of the signal by extrapolating the lines to the zero line (the line passing through the point of excitation of the oscillograph). Measurements by the wide-line method [33] were carried out on a laboratory NMR spectrometer at a frequency of $16 \mathrm{MHz}$.

\section{Results and Discussion}

By the development of new polymeric materials, the modification of epoxy polymers with urethanes is successfully used 
$[34,35]$. The most promising direction here is the oligomer modification containing urethane groups in the chain and epoxy groups at the ends. One of the obstacles for its wide use is the difficulty to obtain the urethane-containing materials using conventional isocyanate technology, which also has its drawbacks such as toxicity of isocyanates, the complexity of their production, storage, processing, and the possibility of side reactions in the presence of even small amounts of water $[31,35]$. Some improvement in processing conditions for epoxy compositions provides the use of blocked isocyanates [36]. Among the known nonisocyanate methods [37, 38] for the preparation of urethane-containing compounds, the urethane-forming reaction "cyclocarbonate-amine" deserves attention. Cyclic carbonates (CC) are a relatively new and poorly studied class of compounds that causes the urgency of the work analysis by methods of their production, reactivity, and methods for modifying polymers [31].

\subsection{Oligomer-Analogous Transformations of Epoxy Oligomers.} Highlighting the main stages of CC synthesis, it should be noted that the carbonatization of glycidyl ethers can be represented as a chemisorption process described by the following equation:

$$
\alpha=1-e^{-k T}
$$

where $\alpha$ is the degree of reactive groups conversion, $T$ is the time, and $K$ is the adsorption coefficient, which is a function of the gas content $(\varphi)$, the rotational speed of the stirrer $(n)$, the fluid viscosity $\left(\nu_{\mathrm{L}}\right)$, and the apparatus diameter $(D)$. The quantitative interrelation of these parameters is established for the process under study [30] by the following equation:

$$
K=1.66\left(\frac{\nu_{\mathrm{L}}}{D^{2}}\right)^{0.088} \cdot \varphi^{0.34} \cdot n^{0.912}
$$

By these studies, the possibility of obtaining oligomeric $\mathrm{CC}$ at both excess and atmospheric pressure was established. Moreover, the process of carbonization at atmospheric pressure can take place not only in solution, but also in the mass with a sufficiently high rate to high degrees of transformation $(\alpha)$ in the range from 120 to $140^{\circ} \mathrm{C}$ and concentration of catalyst $\left(\mathrm{C}_{2} \mathrm{H}_{5}\right)_{4} \mathrm{NJ}$ tetraethylammonium iodide in an amount of no more than $1 \times 10^{-2} \mathrm{~mol} / \mathrm{kg}$. The reaction is described by second-order kinetic equation [39]:

$$
\frac{d x}{d \tau}=K \cdot X Y
$$

where $X$ is the concentration of epoxide groups and $Y$ is the catalyst concentration $\left(C_{\mathrm{c}}\right)$. In the synthesis of the CC, the mass of the reaction mixture $(m)$ increases with increasing conversion $(\alpha)$ and the catalyst concentration $(Y)$ decreases accordingly. Dependence of the change in the mass of the reaction mixture $(m)$ and $\alpha$ is related by the following relation: $m=n_{\mathrm{EO}} \times\left(M_{\mathrm{ER}}+44 \cdot f \cdot \alpha\right)$, where $M_{\mathrm{ER}}$ is the molecular weight of epoxy resins (ER), $f$ is the functionality of the ER, and $n_{\mathrm{EO}}$ is the number of the epoxy oligomer moles in initial time. The obtained experimental data on the interaction of $\alpha$-oxides with $\mathrm{CO}_{2}$ allowed determining the conditions for the oligoethercyclocarbonate preparation, based on epoxy oligomers with different structures (Table 1). The stable quality of the OECC is probably similar due to the oligomeramino conversion of epoxide groups to cyclocarbonate ones. The presence of such a transformation is confirmed by IR spectroscopy data (the peak presence at $1800 \mathrm{~cm}^{-1}$ corresponding to stretching vibrations $>\mathrm{C}=\mathrm{O}$ groups in the $\mathrm{CC}$ ) and chemical analysis (coincidence of the calculated and determined saponification number). After carbonatization, the molecular-weight distribution of epoxy oligomers is practically unchanged inherited by cyclocarbonate oligomers. This was clearly confirmed for the epoxidian oligomer and the corresponding cyclic carbonate DCC/ED-20. It was satisfactorily confirmed also for other epoxy oligomers.

4.2. Structuring of Epoxyurethane Mesh Polymers. The polymer formation process based on epoxy-cyclocarbonate amine curing compositions was determined by the conditions of two basic competing reactions: epoxide-amine, with the formation of a network structure and cyclocarbonateamine, with the formation of linear hydroxyurethane fragments. The variety in the resulting epoxyurethane polymer properties cannot be excluded under the conditions determining the formation of a single polymeric network: a common curing agent (an aliphatic amine) and a close reactivity of epoxy and cyclocarbonate oligomers. By varying the ratio of components and the structure of EC oligomers, it is possible to regulate the cross-link density, polarity, and flexibility of the grid chains formed by chemical bonds. In addition, the modification of OECC epoxy-amine compositions leads to the formation of intermolecular hydrogen bonds involving urethane groups. That can affect the molecular mobility and the level of physical and mechanical properties of polymers (the contribution of a physical bonds network). The totality of the modification processes can be represented step by step as follows.

\subsection{Aminolysis of Cyclic Carbonates and Their Curing} with Epoxy Oligomers. Kinetic studies of the CC aminolysis were performed on the example of the interaction of 1-tetrahydrophenylcarboxy-2,3-propylene carbonate (obtained on the basis of phenyl glycidyl ether (PGE), the content of epoxy groups was $0 \%$, the determined saponification number was 582, and the calculated saponification number was $577, T_{\mathrm{m}}=93^{\circ} \mathrm{C}$, white powder) with benzylamine in chlorobenzene [40]. It is established that the investigated process proceeds by two parallel flows: noncatalytic and catalyzed by two amine molecules. The mechanism of the process can be represented in the following form:

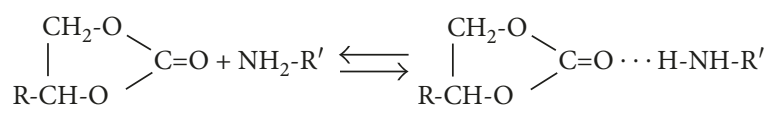

$$
2 \mathrm{R}^{\prime}-\mathrm{NH}_{2} \longleftrightarrow \mathrm{R}^{\prime}-\mathrm{NH}^{\delta-}-\mathrm{H} \cdots \mathrm{NH}_{2}-\mathrm{R}^{\prime}
$$

In the first stage of the process, a formation of associates is possible: a hydrogen-bonded complex of benzylamine 
with a CC and two amine molecules as a result of selfassociation. Further, the catalytic reaction develops with the opening of the cyclocarbonate ring, obviously, through an intermediate cyclic transition state formed by the interaction of the activated amine in the associate and cyclocarbonate in the associate:

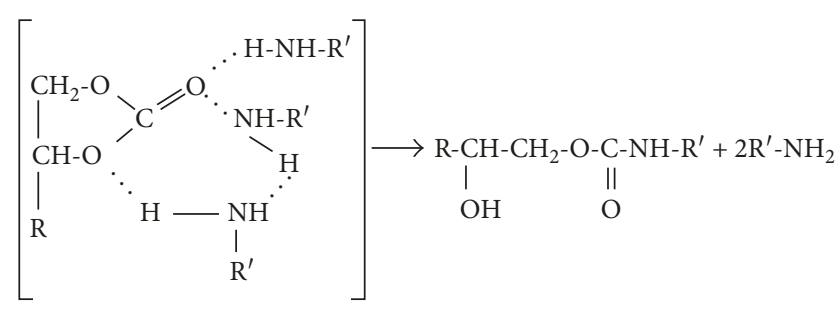

Analogous assumptions about the formation possibility of a cyclic transition compound were also expressed in [41], but with the participation of two amine molecules. In the case of noncatalytic aminolysis, the cyclocarbonate is attacked by the carbonyl carbon atom by one amine molecule. The probability of a cyclic transition state is confirmed by the low activation energy in the catalytic reaction [42], calculated approximately at two temperatures. With a decrease in temperature and an increase in the amine concentration, the catalytic flow contribution increases to the overall process of the CC aminolysis (Table 2).

By real curing conditions of oligomers EO and OECC (when the process is carried out in "mass"), higher reaction rates should be expected, since the amine concentration under these conditions is $4-5 \mathrm{~g} / \mathrm{l}$, which confirms the validity and possibility of using the CC as reactive epoxy modifiers of amine curing compositions.

The curing process of the epoxy and cyclocarbonate oligomer was studied by IR spectroscopy. Comparative studies were performed on aromatic (DCC/ED-20) and aliphatic oligoethercyclocarbonates (DCC/DEG-1 and DCC/ E-181) (Table 3). When curing the (ED-20 + DCC/DEG-1 + DETA) and (ED-20 + DCC/ED-20 + DETA) compositions, a redistribution of the intensities of the absorption bands of $920 \mathrm{~cm}^{-1}$ (epoxy groups), $1802 \mathrm{~cm}^{-1}$ (cyclocarbonate Group), 1700 and $1715 \mathrm{~cm}^{-1}$ (carbonyl groups of urethane fragments) could be considered in IR spectra. This indicates the occurrence of simultaneous reactions over epoxide and cyclocarbonate groups.

In the aminolysis study on model compounds, it was shown that the reaction rate for cyclocarbonate is higher than for epoxy. This conclusion can be confirmed for OECC (with a content of 20 to $30 \%$ ): after 5 minutes, the reaction rate is high (this is indicated by the intense peak of urethane carbonyl), and after 60 minutes, the conversion $(\alpha)$ is about $60 \%$. With an OECC content of more than $30 \%$, the consumption rate of the cyclocarbonate groups decreases and that of the epoxide groups increases (slopes of the curves in Figure 1). This may be a catalytic effect consequence of the hydroxyurethane groups formed.

Further, as a result of the predominant epoxy group interaction, the composite system is depleted by the primary amine. The limiting degree of the CC group transformation
TABLE 2

\begin{tabular}{lccc}
\hline Value & $60^{\circ} \mathrm{C}$ & $80^{\circ} \mathrm{C}$ & $E(\mathrm{~kJ} / \mathrm{mol})$ \\
\hline$C_{\mathrm{o}}\left(1 \cdot \mathrm{mol}^{-1} \cdot \mathrm{min}\right)$ & $5.58 \times 10^{-1}$ & $9.95 \times 10^{-4}$ & 28.3 \\
$C_{\mathrm{v}}\left(1 \cdot \mathrm{mol}^{-1} \cdot \mathrm{min}\right)$ & $9.92 \times 10^{-3}$ & $1.14 \times 10^{-2}$ & 6.8 \\
\hline
\end{tabular}

Note. $C_{\mathrm{o}}$ is the noncatalytic constant of the CC bimolecular interaction on the PGE basis and $C_{\mathrm{v}}$ is the catalytic rate constant.

decreases since the interaction with the secondary CC amines at 20 to $22^{\circ} \mathrm{C}$ is very slow. This conclusion is confirmed by the fact that with an excess of amine (1.2 to 1.3 from stoichiometry), the degree of reactive group conversion increases sharply, and after 5 to $8 \mathrm{~h}$ (for cyclocarbonate) and 16 to $20 \mathrm{~h}$ (for epoxy), changes in the intensity of the characteristic bands almost do not occur. After $24 \mathrm{~h}, \alpha$ is 90 to $95 \%$ (for cyclocarbonate) and 80 to $90 \%$ (for epoxy) groups. The noted signs of inhibition due to the network polymer solidifying [43] are also retained when the OECC is modified, reaching $\alpha \approx 70$ to $75 \%$. The properties of unmodified epoxy-amine polymers stabilize after 5 to 7 days, but they do not reach the level of polymers characteristic for highly cured polymers $\left(22^{\circ} \mathrm{C}\right.$ with $24 \mathrm{~h}$ and $100^{\circ} \mathrm{C}$ with $10 \mathrm{~h}$ ) (Table 3).

For systems containing DCC-DEG-1, this difference is insignificant, which is quite convincing evidence of the effect of modification.

It should be noted that with polymer characteristics improvement $\left(\sigma_{\mathrm{p}}, \varepsilon_{\mathrm{p}}\right.$, and $\left.T_{\mathrm{c}}\right)$, the adhesive properties also increase $\left(T_{\mathrm{B}}\right.$ and $\left.\sigma_{\text {p.o }}\right)$. This result is worthy of note, since Lipatov et al. noted $[44,45]$ that epoxy-amine systems have a low adhesive strength as a result of the weak boundary layer formation due to the selective sorption of epoxy polymers on high-energy hard surfaces. This, as a consequence, leads to a violation of the stoichiometry of the components and the lack of solidification of the composition in the boundary layer.

To compare the adhesive strength in the boundary layers of the systems (Table 4), the IR absorption spectroscopy in absorption $(1,2)$ and ATR arrangement $\left(1^{\prime}, 2^{\prime}\right)$ was used (Figure 2). It can be considered that for the unmodified system, the degree of reactive epoxy groups conversion $(\alpha)$ was $72 \%$ and in the boundary layer $36 \%$ (high free surface energy-element KRS-5). For systems modified with $20 \%$ DCC/DEG-1, the values $\alpha$ for epoxy groups are relatively close to $72 \%$ and $62 \%$, respectively. These results make it possible to understand not only the reasons for the increase in adhesion strength as a result of the OECC modification, but also the previously described aminolysis features of the CC and EO. As noted above, in the first minutes of mixing oligomers with an amine hardener, a significant amount of urethane groups are formed in the system, which are capable to blocking the active centers of the substrate solid surface. It prevents the selective sorption of EO and weak boundary layers formation after the composition is applied.

4.4. The Contribution of Hydroxyurethane Fragments to the Epoxy Polymer Properties. The topological structure studies, formed by epoxy-amine mesh modification with cyclic carbonate containing hydroxyurethane fragments were 
TABLE 3: Physicomechanical properties of polymers obtained under different conditions of curing epoxy-amine compositions.

\begin{tabular}{|c|c|c|c|c|c|c|}
\hline \multirow{2}{*}{ Composition } & \multirow{2}{*}{ Curing mode } & \multicolumn{5}{|c|}{ Physical and mechanical properties } \\
\hline & & $\sigma_{\mathrm{p}}(\mathrm{MPa})$ & $\varepsilon_{\mathrm{p}}(\%)$ & $\tau_{\mathrm{B}}(\mathrm{MPa})$ & $\sigma_{\text {p.o }}(\mathrm{MPa})$ & $T_{\mathrm{c}}\left({ }^{\circ} \mathrm{C}\right)$ \\
\hline \multirow{2}{*}{ ED-20 + DETA } & $7 \mathrm{~d}$ at $\left(22 \pm 2^{\circ} \mathrm{C}\right)$ & 20.7 & 0.6 & 4.6 & 8.8 & 46 \\
\hline & $1 \mathrm{~d}$ at $\left(22 \pm 2^{\circ} \mathrm{C}\right)$ and $10 \mathrm{~h}$ at $100^{\circ} \mathrm{C}$ & 72.5 & 2.5 & 12.5 & 28.0 & 108 \\
\hline \multirow{2}{*}{ ED-20 + DCC/DEG-1 + DETA } & $7 \mathrm{~d}$ at $\left(22 \pm 2^{\circ} \mathrm{C}\right)$ & 75.2 & 5.2 & 15.8 & 30.5 & 42 \\
\hline & $1 \mathrm{~d}$ at $\left(22 \pm 2^{\circ} \mathrm{C}\right)$ and $10 \mathrm{~h}$ at $100^{\circ} \mathrm{C}$ & 88.3 & 4.4 & 22.8 & 50.0 & 68 \\
\hline
\end{tabular}

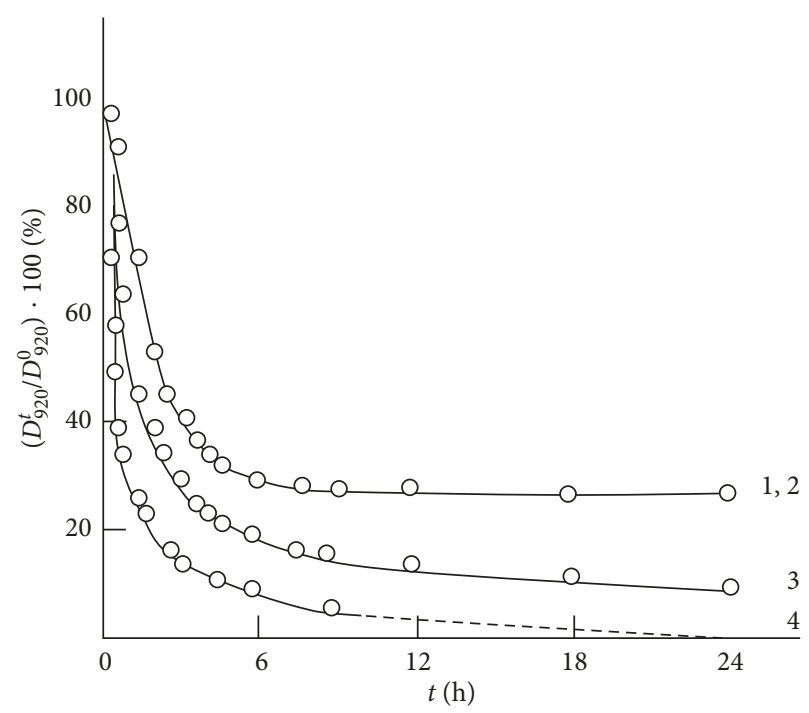

(a)

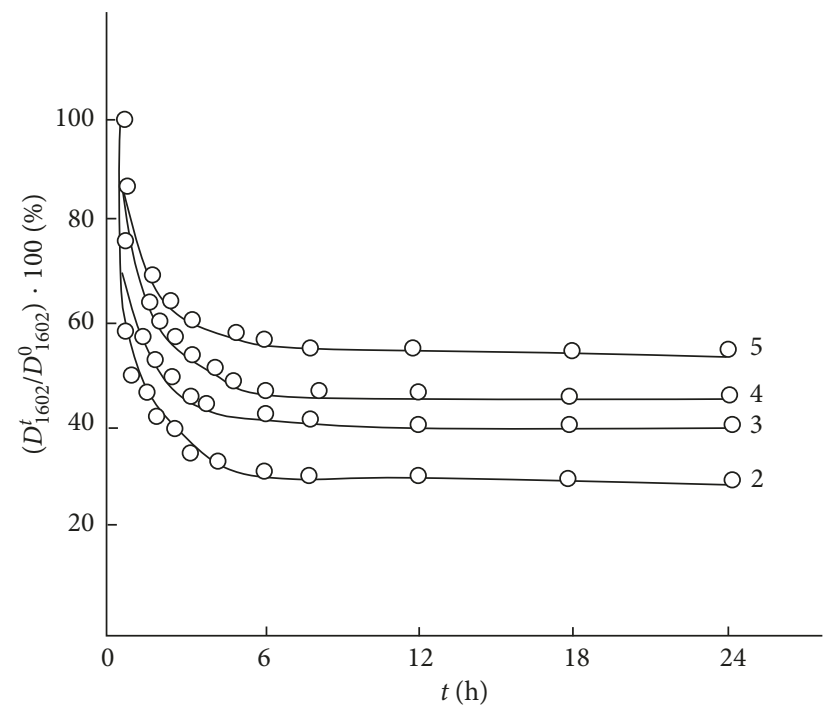

(b)

Figure 1: Changes in the content of epoxide (a) and cyclocarbonate groups (b) during the curing of ED-20 + DCC/DEG-1 + DETA compositions as a function of the DCC/DEG-1 content with $0 \%$ (1), 20\% (2), 40\% (3), 50\% (4), and 60\% (5).

TABLE 4: Influence of modifiers (20\% OECC) and ED-20 + DETA composition curing at the second moment of NMR absorption.

\begin{tabular}{lcc}
\hline Composition & \multicolumn{2}{c}{$\begin{array}{c}\text { Second moment of NMR } \\
\text { absorption }\end{array}$} \\
& $\begin{array}{c}\text { Curing } 7 \mathrm{~d} \\
\text { at } 22^{\circ} \mathrm{C}\end{array}$ & $\begin{array}{c}\text { Postcuring } 10 \mathrm{~h} \\
\text { at } 100^{\circ} \mathrm{C}\end{array}$ \\
\hline ED-20 + DETA & 4.50 & 2.50 \\
ED-20 + DCC/ED-20 + DETA & 4.50 & 5.20 \\
ED-20 + DCC/DEG-1 + DETA & 1.68 & 2.70 \\
\hline
\end{tabular}

performed by IR spectroscopy and a number of relaxation methods. As noted above, the disadvantage of unmodified epoxy-amine compositions is their high stiffness (brittleness), which results in low cohesive strength, especially for cured compositions without heat input (Table 3). The cohesive strength depends on both the density of the chemical bonds network and the intermolecular interaction forces (a grid of physical bonds) in the glassy state. The increase in rigidity and heat resistance (to a greater extent for polymers cured at $T<22^{\circ} \mathrm{C}$ ) mainly depends on intermolecular interactions (IMI) in chains and packing of aromatic nuclei. Based on these provisions, it was of interest to determine the manifestation and relative level of these factors in the initial epoxy-amine system, and

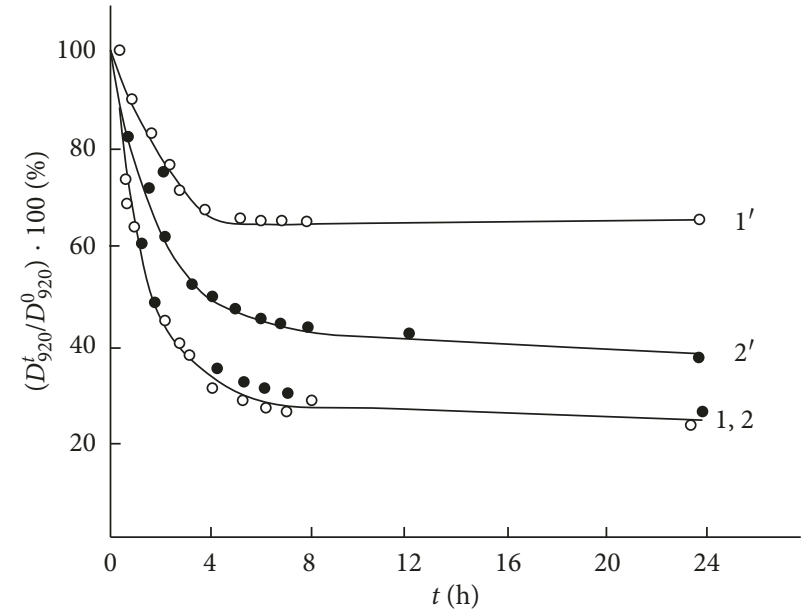

FIgURE 2: The change in the content of unreacted epoxy groups during the curing of ED-20-DETA $\left(1,1^{\prime}\right)$ and ED-20 + DCC/DEG$1+\operatorname{DETA}\left(2,2^{\prime}\right)$ compositions, determined by IR transmission spectroscopy $(1,2)$ and ATR-IR $\left(1^{\prime}, 2^{\prime}\right)$.

to follow the changes that occur during the modified compositions curing.

Controlling the optical density and the integrated intensity of the complex deformation vibration in benzene 
ring bands (wavenumbers of $1612 \mathrm{~cm}^{-1}$ and $1584 \mathrm{~cm}^{-1}$ ), which are sensitive to changes in the universal intermolecular interaction of aromatic nuclei, the changes occurring during glass transition of the systems were followed. During the ED-20+DETA compositions curing process, an increase in the integrated intensity of the spectral contour in the frequency range of 1570 to $1650 \mathrm{~cm}^{-1}$ was observed. This is proportional to the change in the optical density of $1612 \mathrm{~cm}^{-1}$ band $\left(D_{1612}\right)$, which indicates the enhancement of the aromatic nuclei IMI.

The $D_{1612}$ values by curing for $3 \mathrm{~d}$ at $22^{\circ} \mathrm{C}$ increase from 0.681 to 0.724 , and after curing for $8 \mathrm{~h}$ at $100^{\circ} \mathrm{C}$ they decrease to 0.685 . These results indirectly indicate a change in the stiffness and molecular mobility of the polymer structure elements, which is also confirmed by data determined from the second magnetic moments values of NMR absorption $\left(M_{2}\right)$. It is known [32] that the larger the value of $M_{2}$ indicates the lower molecular mobility. A polymer based on an unmodified epoxy-amine composition cured at $22^{\circ} \mathrm{C}$ is characterized by a high level of $M_{2}$ values with $4.5 E^{2}$, which decreases after postcuring at $100^{\circ} \mathrm{C}$ (Table 4 ). According to these results, the additional curing should help increase the chemical bonds number and further increase the rigidity of the polymer. Can this fact be explained?

For more rigid epoxy-amine systems containing slowmoving polyhedra fragments, it was shown that by amine curing without additional heat input, linear polymer chains are predominantly formed in the composition as a result of the predominant interaction of more active primary amino groups with epoxy groups EO (with the example of bisphenol A diglycidyl ether). The resulting linear chains are capable of denser packaging, in particular aromatic nuclei (in the case of adamantanes, bulk cycloaliphatic fragments), which determines the high rigidity of the polymer. The postcure at $T>T_{\mathrm{c}}$ not only leads to an increase in the cross-linking frequency (over the secondary amino groups), but also to the destruction of the formed ordered structures [46] and, consequently, to a polymer rigidity reduction.

For example, when the ED-20+DETA composition is modified with an aromatic OECC, the structure of the newly formed polymer is characterized by the presence of urethane groups and a lower cross-linking frequency $\left(\eta_{\mathrm{c}}\right)$. However, despite a slight decrease in $\eta_{c}$, the rigidity of the limit-cured polymer is much higher $\left(M_{2}=5.2 E^{2}\right)$ than for an unmodified polymer. This unambiguously demonstrates the contribution of urethane groups to an increase in stiffness and a decrease in molecular mobility. Comparing with the stiffness of modified aliphatic OECC, it can be seen that the level for polymers cured at $22^{\circ} \mathrm{C}$ with $M_{2}=1.68 E^{2}$ is much lower, and after the hardening, the $M_{2}$ value is close to the level of the highly cured unmodified polymer. This is obviously a consequence of the combined effect of high-polar urethane groups (decreased mobility) and flexible diethylenic fragments (increased mobility). According to the values of $M_{2}$, the optical density of the band is $1612 \mathrm{~cm}^{-1}$ and the values of $D_{1612}$ increase during the curing process from 1.145 to 1.205 and 1.252 (after the postcuring), which corresponds to the increase in rigidity of the system. Thus, the cumulative effect is that the introduction of an aliphatic modifier into the composition increases the system deformation reserves and reduces the overall level of its rigidity (from $M_{2}=4.50 E^{2}$ to $M_{2}=1.68 E^{2}$ ), which provides a high level of cohesive strength of the polymers also curing without additional heat (Table 3 ).

The evidence for the urethane group role for increasing the system rigidity can be confirmed by an experiment with the blocking of these groups by lithium chloride (4\% solution in dimethylformamide, taken in the stoichiometric ratio to the calculated number of urethane groups). The composition as well as the cured polymer remained transparent, when combined with $\mathrm{LiCl}$ and after the addition of the hardener. The $\mathrm{Li}^{+}$and $\mathrm{Cl}^{-}$ions block the $>\mathrm{C}=\mathrm{O}$ and $\mathrm{NH}-$ groups formed during the curing, excluding (in part or in whole) the intra- and intermolecular interactions. The data obtained clearly illustrate the effect of polymer hardening due to physical interactions of urethane groups (Table 5). The performed experiment indicates that the hydrogen bonds in the studied epoxy polyurethane combinations have a significant influence not only on the processes of polymer formation but also on their macroscopic properties. For unmodified epoxy-amine polymers, the greater contribution of hydrogen bonds to the macroscopic properties of polymers should be expected in the temperature range below the $\beta$ transition [28]. The linear homo- and copolymers of styrene and methacrylates showed [47] that the $\beta$-transition "loosens up" the hydrogen bonds and leads to their partial destruction. The hydrogen bonds shift $T_{c}$ to higher temperatures, preventing large-scale molecular motion.

The molecular mobility in the range from -100 to $+200^{\circ} \mathrm{C}$ has been studied by the dielectric relaxation method. It was established that for the investigated polymers, two different transitions are the low-temperature transition in the range from -70 to $+100^{\circ} \mathrm{C}$, corresponding to the processes of dipole-group $\beta$-relaxation, and high-temperature transition by $T>+100^{\circ} \mathrm{C}$, corresponding to dipole-segmental $\alpha$-relaxation (Figure 3 ). It can be seen from the relaxation curves that the $\beta$-relaxation peak intensity decreases with an increase in the OECC concentration (partial degeneration of the $\beta$-transition was observed). It can be assumed that the intra- and intermolecular hydrogen bonds of the hydroxyl groups on the urethane group carbonyl $(-\mathrm{OH} \cdots \mathrm{O}=\mathrm{C}<$ ) prevent the internal rotation. The defrosting of these movements obviously occurs with the onset of the polymer melting. An increase in the $M_{2}$ NMR absorption values, the degeneration of the $\beta$-transition, and a sharp decrease in the deformation-strength characteristics for the ED-20 + DCC/ED-20 + DETA system indicate a decrease in the molecular mobility in the glassy state. In the highly elastic state, its increase is obviously associated with the rotation of hydrogen-bonded hydroxyurethane fragments during "defrosting" of the aromatic nuclei movements (with the $\alpha$-relaxation process). This is manifested by an increase in the intensity of the $\alpha$-transition peak on the dielectric relaxation curves and the appearance of a second (longer) NMR relaxation time at $T>T_{\mathrm{c}}$. Modification of aliphatic DCC/DEG-1 (graph 3 in Figure 3) differs from the 
TABLE 5: Effect of blocking of urethane groups by $\mathrm{LiCl}$ on the epoxy polymer properties.

\begin{tabular}{lccccc}
\hline & \multicolumn{5}{c}{ Properties of polymers } \\
Composition & $\begin{array}{c}\sigma_{\mathrm{p}} \\
(\mathrm{MPa})\end{array}$ & $\begin{array}{c}\varepsilon_{\mathrm{p}} \\
(\%)\end{array}$ & $\begin{array}{c}\tau_{\mathrm{B}} \\
(\mathrm{MPa})\end{array}$ & $\begin{array}{c}\sigma_{\mathrm{p} . \mathrm{o}} \\
(\mathrm{MPa})\end{array}$ & $\begin{array}{c}\mathrm{T}_{\mathrm{c}} \\
\left({ }^{\circ} \mathrm{C}\right)\end{array}$ \\
\hline $\begin{array}{l}\text { ED-20 + DETA with 20\% } \\
\text { DCC/DEG-1 }\end{array}$ & 88.3 & 4.4 & 22.8 & 50.0 & 68 \\
$\begin{array}{l}\text { ED-20 + DETA with 20\% } \\
\text { DCC/DEG-1 and 4\% LiCl }\end{array}$ & 62.4 & 5.1 & 20.5 & 32.2 & 38 \\
\hline
\end{tabular}

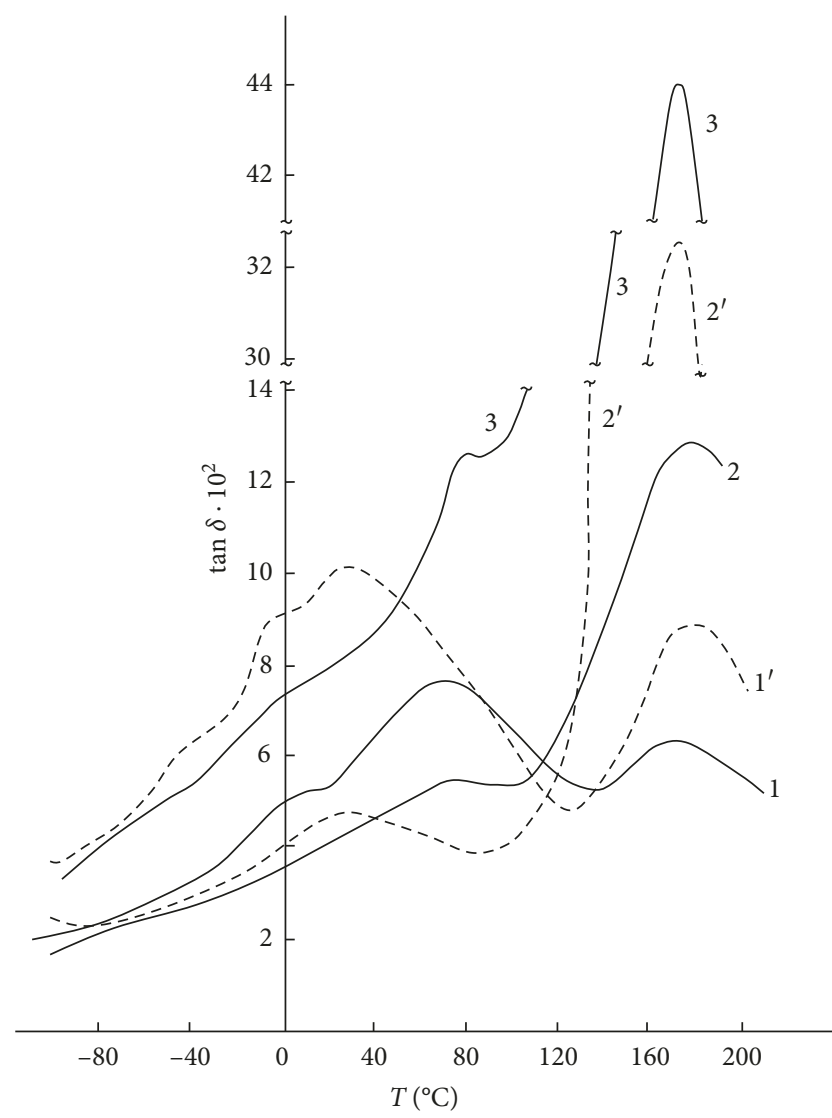

Figure 3: The temperature dependence of the dielectric loss angle tangents at a frequency of $10^{6} \mathrm{~Hz}(1-3)$ and $10^{5} \mathrm{~Hz}\left(1^{\prime}, 2^{\prime}\right)$ for polymers obtained on the basis of the modified ED-20 + DETA (1, $\left.1^{\prime}\right)$, modified $20 \%$ DCC/ED-20 (2, $\left.2^{\prime}\right)$, and $20 \%$ of DCC/DEG-1 (3).

considered variant in the presence of mobile diethylene glycol units in the polymer structure, increasing its molecular mobility in both glassy and highly elastic states.

A characteristic feature of most epoxy-amine compositions is the two-component decrease in magnetization during their curing, with the appearance of the transverse relaxation times $T_{2 \mathrm{a}}$ and $T_{2 \mathrm{~b}}$ (Figure 4 ) in the initial stage of the induction period. The isolated relaxation times $T_{2 \mathrm{a}}$ and $T_{2 b}$ decrease monotonically and are combined in one short time $T_{2}$ at a level of 10 to $20 \mu$ s during the reaction proceeding. This is characteristic for rigid polymers with frozen segmental mobility. However, the yield of $T_{2}$ values at this level does not mean the completion of the structure formation processes, as evidenced by the high values of $P_{\mathrm{a}}$ in the range of 0.4 to 0.5 , which are retained by the glass transition of the polymers (Figures 4 and 5).

High values of $P_{a}$ indicate the intermolecular interactions enhancement, as well as the molecular mobility limitation. Analyzing the data of NMR spectroscopy, some peculiarities for polymer system behavior (before gelation) should be noted. First, the induction period decreases, and at $20 \%$ to $30 \%$ of the OECC, it is already absent, which can be explained by the reaction acceleration due to the realization of the OECC catalytic aminoalkylation reaction. Secondly, the time for achieving the glassy state is shortened and the rate of in the dynamic rigidity increase for the system is raised. This is apparently not only the catalytic process consequence, but also a consequence of polarity increase in the polymer chains due to the formation of urethane groups. A similar picture was observed in other epoxyurethane systems. Thirdly, the values of $P_{\mathrm{a}}$ significantly decrease up to 0.30 (Figure 4).

A comparison on the transverse relaxation times of ultimately cured polymers and temperature dependence data shows that unmodified epoxide-amine polymers have only one time $T_{2}$ in a wide temperature range form +22 to $+200^{\circ} \mathrm{C}$. The appearance of the time $T_{2 \mathrm{a}}$ is obviously associated with the formation of hydroxyurethane fragments. The molecular mobility changes with increasing temperature (transition to a highly elastic state) in accordance with the polymer structure, for example, the beginning and completion of the increase in $T_{2}$ level for unmodified (Figure 6, graph 1) and modified with aromatic OECC (Figure 6, graph 2) polymers differ from polymers modified with aliphatic OECC (Figure 6, graph 3). Moreover, in the case of modification with aliphatic OECC, the time $T_{2 \mathrm{a}}$ was detected much earlier (at $120^{\circ} \mathrm{C}$ ), and the changes in the levels of $T_{2 a}$ and $T_{2 b}$ occur simultaneously. This is typical for a nonuniform structure, but a uniform polymer network. Obviously, the time $T_{2 \mathrm{a}}$ corresponds to elongated internode chains containing hydroxyurethane fragments. The molecular motion in them is initiated by the $\beta$-relaxation process by "loosening" the hydrogen bonds formed by urethane and hydroxyl groups.

\section{Discussion}

The formation processes study of the developed system for the hydrogen bonds (network of physical bonds), a decrease in molecular mobility in the glassy state and an increase in the highly elastic state, allows to understand the causes of the change in the relaxation and physicomechanical properties of polymers due to the "discharge" of the chemical bonds network by the modification of hard epoxy-amine compositions by oligoethercarbonates, containing aromatic and aliphatic links. The choice of the modifying by OECC and the change in the ratio of components allow influencing the frequency of cross-linking, the polarity, the flexibility of fragments and chains and, as a consequence, the rigidity of epoxy polymers and adhesives. For example, the level of polymer hardness modified by aliphatic OECC (Table 4) is much lower $\left(M_{2}=1.62 E^{2}\right)$ than unmodified or modified by 

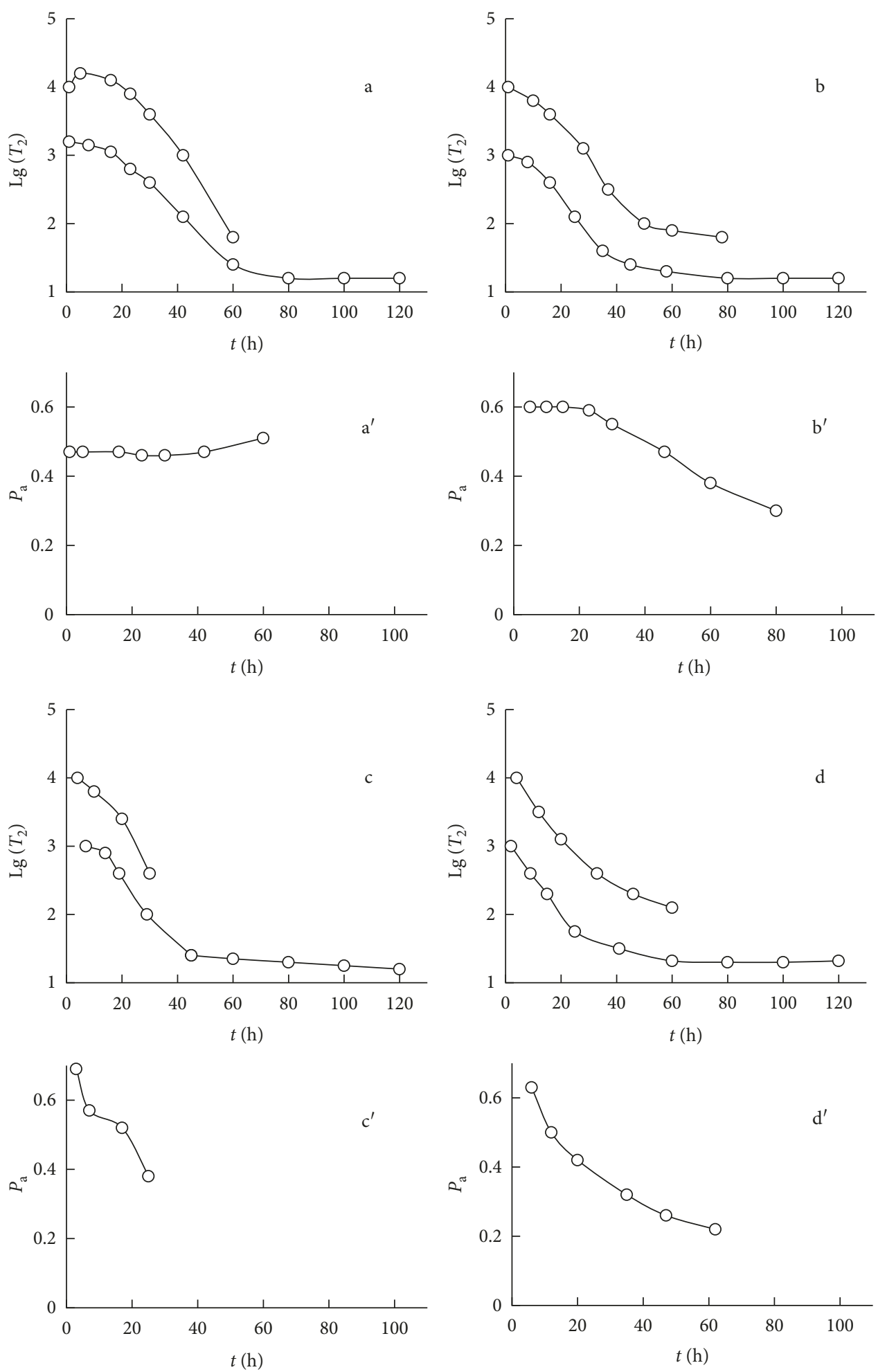

FIGURE 4: Change in the transverse relaxation times $(a-d)$ and the protons population of the mobile "phase" (a-d) during the curing of ED$20+$ DCC/DEG-1 + DETA with the content of DCC/DEG-1: 0\% (a, $\left.a^{\prime}\right), 10 \%\left(b, b^{\prime}\right), 20 \%\left(c, c^{\prime}\right)$, and $50 \%\left(d, d^{\prime}\right)$.

aromatic OECC. When the polymer is postcured, the combined effect of urethane groups is realized: the manifestation and contribution of physical bond network (reduced mobility) and flexible diethylenic fragments (increased mobility).
The observed changes are evidently due to the rotation of hydrogen-bonded hydroxyurethane fragments during defreezing of the aromatic nuclei movements (in the $\alpha$-relaxation process). This is manifested in an intensity increase of the $\alpha$-relaxation transition peak (Figure 3, graph 2, $2^{\prime}$ ) and the 

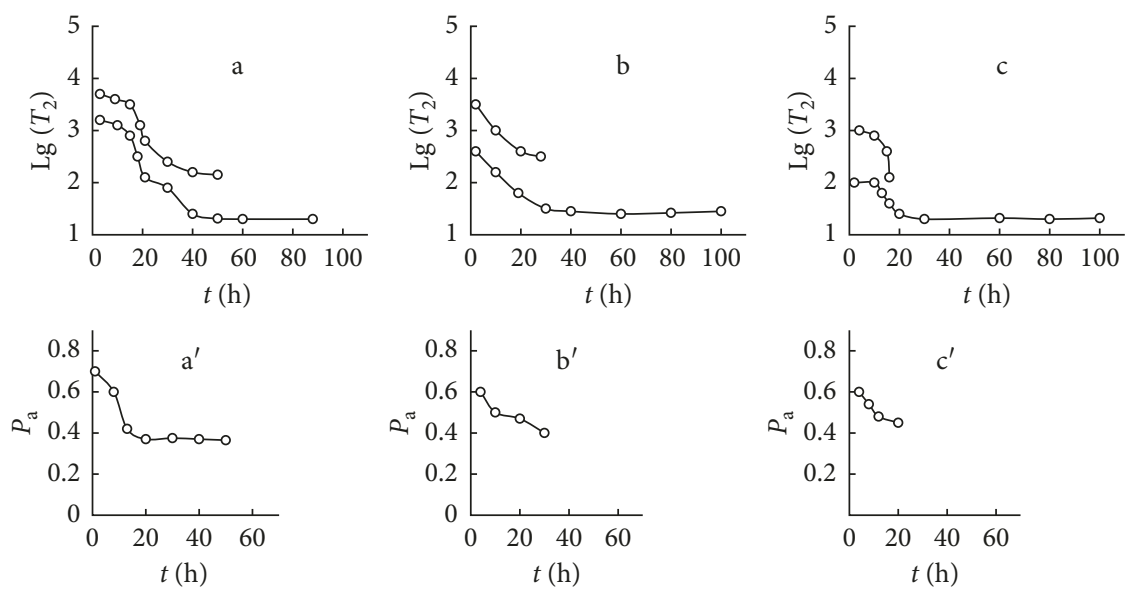

FIGURE 5: Change in the transverse relaxation times $(\mathrm{a}-\mathrm{c})$ and the population of the mobile "phase" protons $\left(\mathrm{a}^{\prime}-\mathrm{c}^{\prime}\right)$ during the curing of ED$20+$ DCC/ED-20 + DETA composition with a content of DCC/ED-20: 10\% (a, $\left.\mathrm{a}^{\prime}\right), 20 \%\left(\mathrm{~b}, \mathrm{~b}^{\prime}\right)$ and $30 \%\left(\mathrm{c}, \mathrm{c}^{\prime}\right)$.

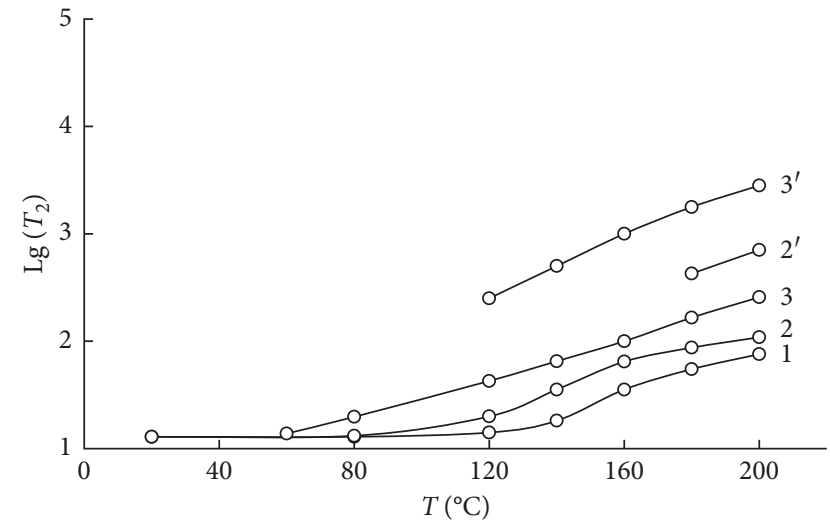

FIgURE 6: Temperature dependences of transverse relaxation times for polymers, based on ED-20 + DETA (1), ED-20 + DCC/ED-20 $+\operatorname{DETA}\left(2,2^{\prime}\right)$ ED-20 + DCC/DEG-1 + DETA $\left(3,3^{\prime}\right) 20 \%$ OECC.

appearance of the second (longer) NMR relaxation time at $T>T_{\mathrm{c}}$ (Figure 6). The introduction of aromatic DCC/ED-20 (solid and as evidenced by the presence on the wide-angle $\mathrm{X}$-ray diffractogram of only amorphous halos, amorphous product) leads to a sharp reduction in the deformation reserves of the polymer (despite the reduction in the crosslinking frequency), which is accompanied by a drop in the physicomechanical characteristics of the polymer: $\sigma_{\mathrm{p}}=20.0 \mathrm{MPa}$, and $\varepsilon_{\mathrm{p}}=0.3 \%$ (Table 6), that is, significantly lower than for the unmodified ED-20+DETA (Table 6, Figure $7(\mathrm{a}))$ with $\sigma_{\mathrm{p}}=75.2 \mathrm{MPa}$ and $\varepsilon_{\mathrm{p}}=2.5 \%$. A similar manifestation of macroscopic properties is observed when aliphatic OECC are used in the concentration range from 15 to $30 \%$ (Figures 7-9).

The widely used in practice epoxy composition modification with aliphatic epoxy oligomers (e.g., DEG-1) is less effective. Comparison of the absolute indicators level in Figures 7(b) and 10 clearly demonstrates a more significant contribution of the urethane component in the application of aliphatic OECC. The use of different OECC structures (DCC/DPG, DCC/COC, and DCC/E-181) gives similar dependences in physicomechanical properties,
TABLE 6: Mechanical properties of polymers based on epoxy compositions modified by OECC and cured DETA.

\begin{tabular}{lccccc}
\hline OECC & \multicolumn{5}{c}{$\sigma_{\mathrm{p}}(\mathrm{MPa}) / \varepsilon_{\mathrm{p}}(\%)$ of polymers by ratio OE: OECC } \\
type & $100: 0$ & $90: 10$ & $80: 20$ & $70: 30$ & $60: 40$ \\
\hline Aromatic & $72.5 / 2.5$ & $42.0 / 0.8$ & $20.0 / 0.3$ & $8.0 /-$ & - \\
Aliphatic & $72.5 / 2.5$ & $82.5 / 2.3$ & $88.3 / 4.4$ & $77.0 / 2.8$ & $55.0 / 5.0$ \\
\hline
\end{tabular}

which differ in the positions of the maxima (Figures 8, 9, and 11).

A number of examples on the practical application convincingly confirm the OECC modification effectiveness of epoxy-amine compositions and the perspectives of their application in solving a number of problems in polymer materials science. For example, for technologies of adhesive bonding parts with large tolerances, in honeycomb structures, lightweight products, and so on, operated in the temperature range from -150 to $+200^{\circ} \mathrm{C}$, fast-setting foam-adhesives have been developed. These adhesives have a relative low density $\left(0.45 \mathrm{~g} / \mathrm{cm}^{3}\right)$ and higher strength (1.5 times) and adhesion (2 times) compared to the known foam-adhesives VK-9V and CW2513, HM, and DY050 (manufacturer Ciba Geigy).

A low viscosity composition based on a mixture of aliphatic and aromatic EO, aliphatic OECC, and a mixture of amine- curing agent for the reinforced concrete structures repair was developed. Due to the elimination of the selective sorption effect for the composition components, it was possible to ensure the reliability of products (water pipes with a diameter of $2000 \mathrm{~mm}$ and a length of $6000 \mathrm{~mm}$ ), which is evaluated under hydraulic tests at a pressure of 1.0 MPa. This composition combines low viscosity $(0.6 \mathrm{MPa} \cdot \mathrm{s})$ with high adhesion and deformation characteristics: for steel and glass-ceramic up to $27.0 \mathrm{MPa}$ (concrete breaks at lower loads), $\sigma_{\mathrm{p}}$ up to $50 \mathrm{MPa}, \varepsilon_{\mathrm{p}}=5 \%$, which is comparable or superior to the analog Araldite K-79 Kit (manufacturer Ciba Geigy). A number of the "Vicor-UP"-type compositions have been developed for corrosion protection of chemical equipment operating under conditions of 5 to $30 \%$ mineral acids solutions (hydrochloric, sulfuric, and phosphoric acids) at 


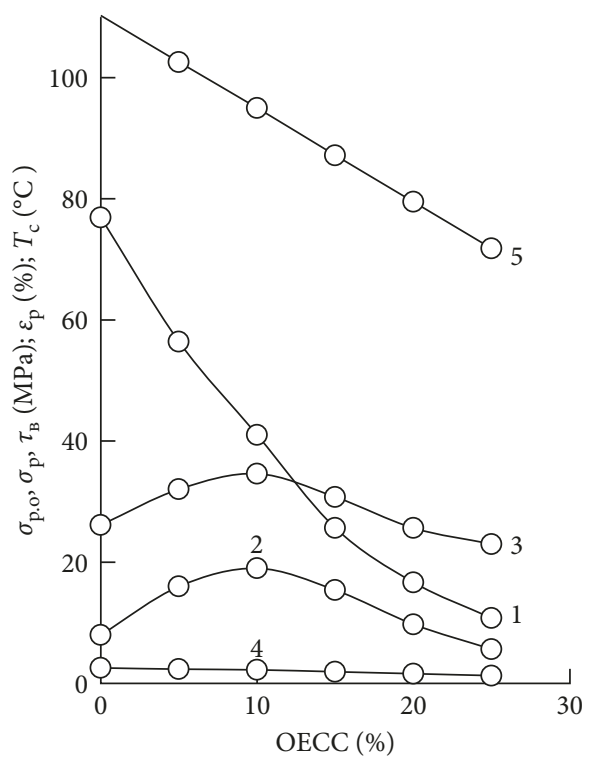

(a)

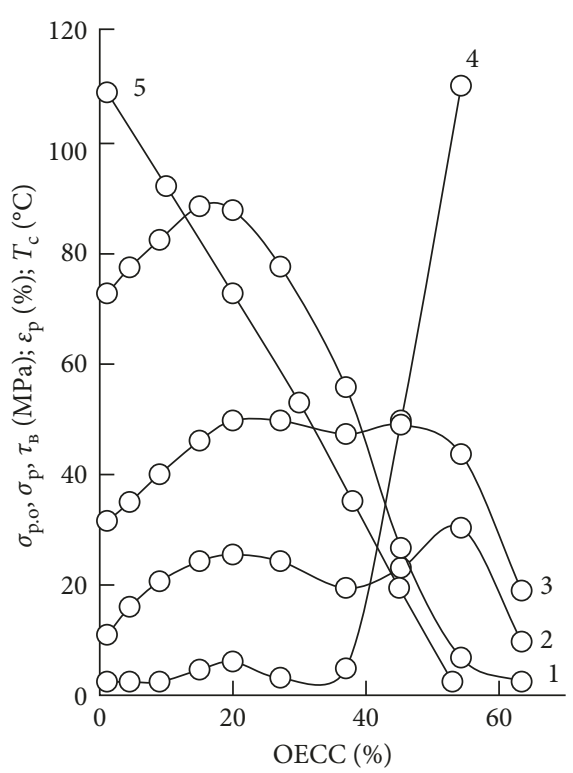

(b)

Figure 7: Dependence of the epoxyurethane polymer properties on the basis of ED-20 + DCC/ED-20 + DETA (a) and ED-20 + DCC/DEG$1+\operatorname{DETA}(\mathrm{b})$ on the OECC modifying concentration, $\sigma_{\mathrm{p}}(1), \tau_{\mathrm{B}}(2), \sigma_{\mathrm{p} . \mathrm{o}}(3), E_{\mathrm{p}}(4)$, and $T_{\mathrm{c}}(5)$.

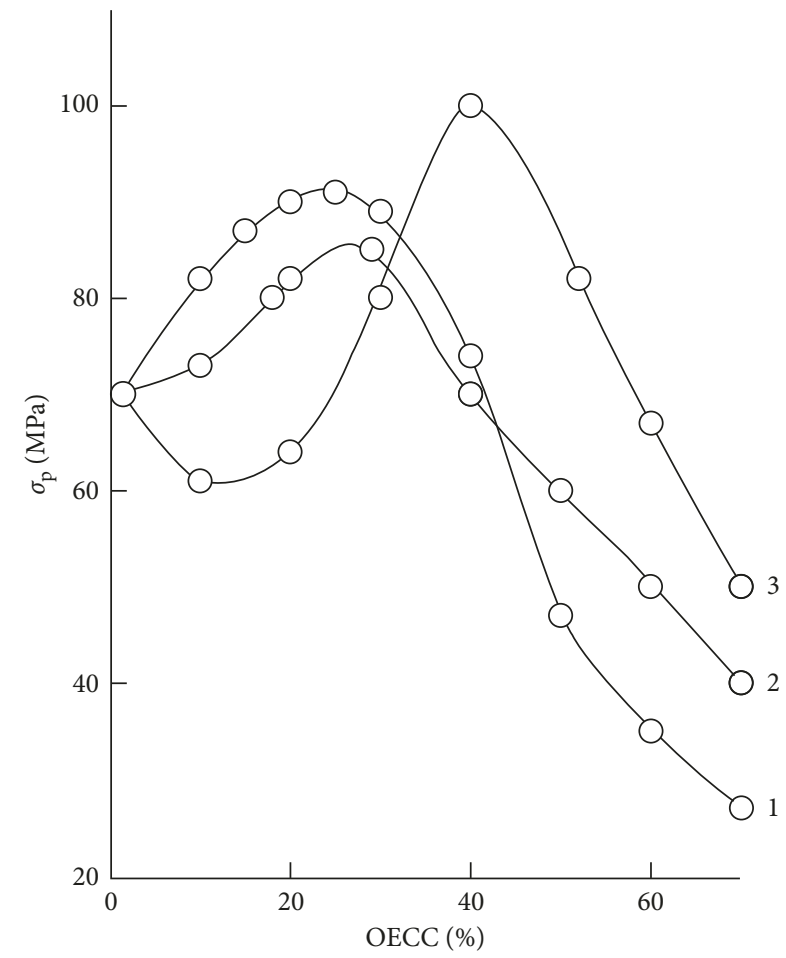

FIGURE 8: Dependence of the tensile strength of polymers obtained on the basis of ED-20+OECC + DETA compositions, on the concentration and modifier type DCC/UP-675 (1), DCC/UP-650D (2), and DCC-181 (3).

$+120^{\circ} \mathrm{C}$, as well as for cold-drying technology. The composition and technology of polymer-sand mandrels obtaining with an increased (by 1.5 times) strength, by reducing thickness and mass, in the technology of manufacturing

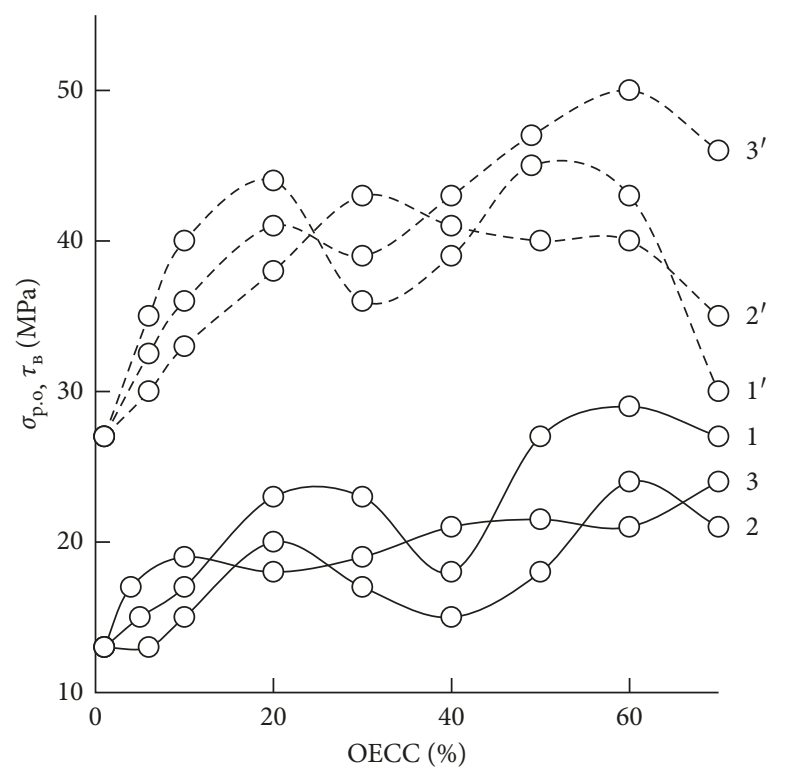

FIgURE 9: Dependence of the adhesive properties of the ED-20 + OECC + DETA compositions on the concentration and modifier type: DCC/UP-675 $\left(1,1^{\prime}\right)$, DCC/UP-650D $\left(2,2^{\prime}\right)$, and DCE-181 $\left(3^{\prime}\right): \tau_{\mathrm{B}}(1-3)$ and $\sigma_{\text {p.o }}\left(1^{\prime}-3^{\prime}\right)$.

products have also been developed. These applications testify the wide possibilities for OECC as modifiers in epoxy-amine compositions in various technologies and prospects for the research and development in this direction.

\section{Conclusions}

One of the promising directions of epoxy-amine network polymers, in order to eliminate their "hardness," is the 


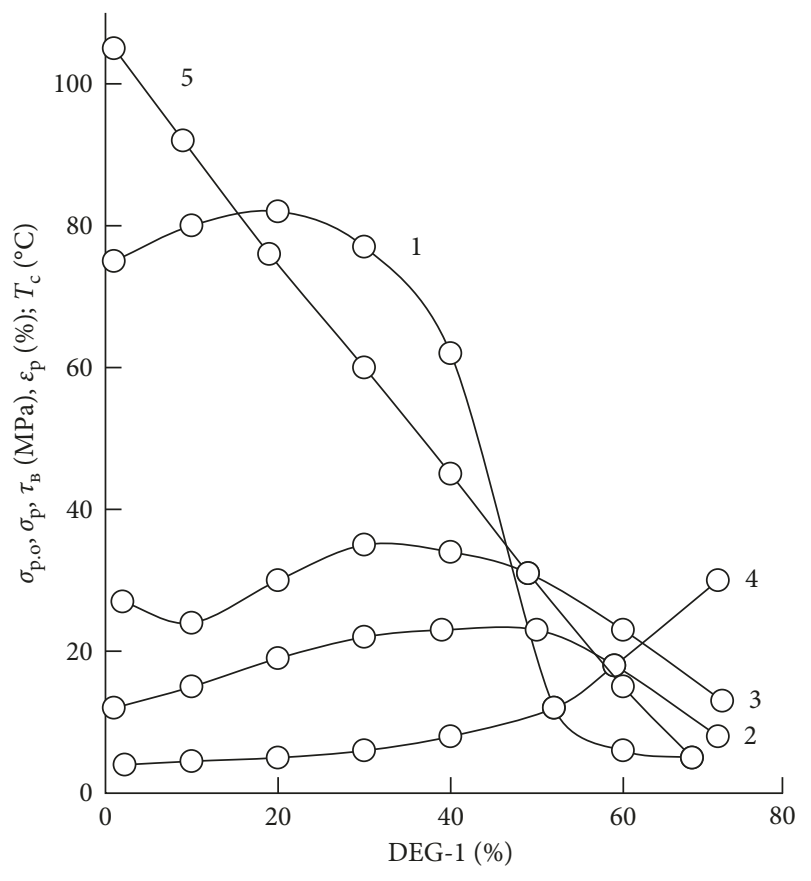

FIGURE 10: The effect of the DEG-1 content in the composition of ED-20 + DEG-1 + DETA on the properties of polymers: $\sigma_{\mathrm{p}}(1)$, $\tau_{\text {в }}(2), \sigma_{\text {p.o }}(3), \varepsilon_{\mathrm{p}}(4)$, and $T_{\mathrm{c}}(5)$.

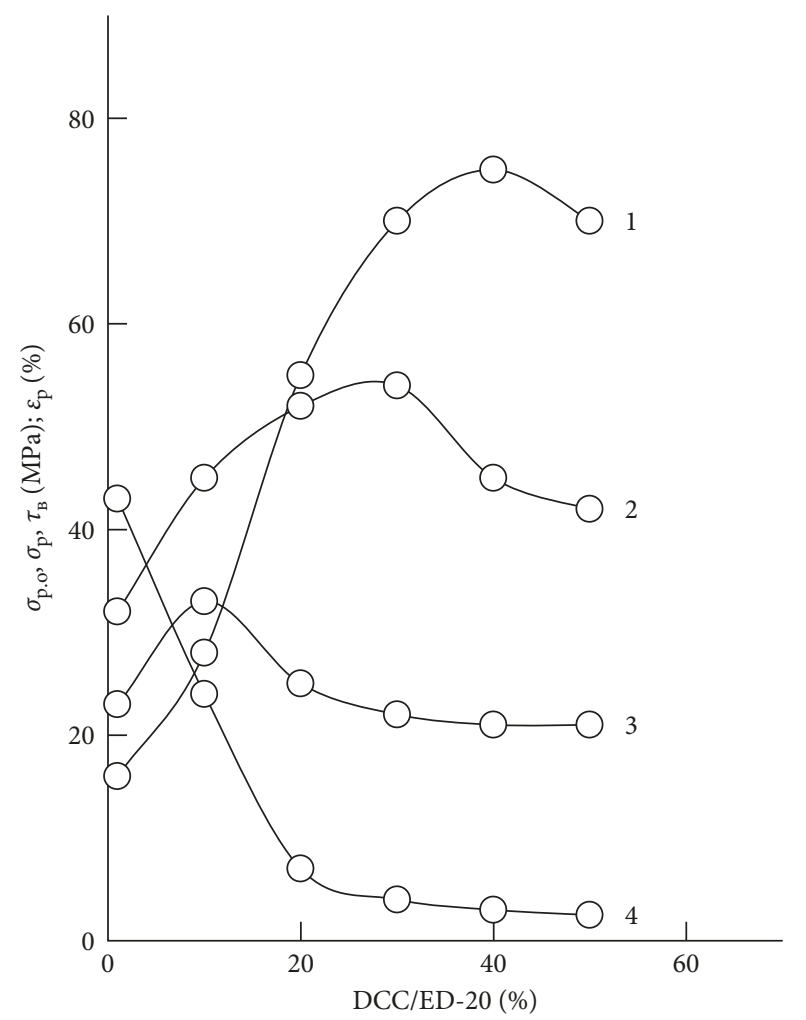

Figure 11: Dependence of the mechanical and adhesion properties of polymers obtained on the basis of the E-181 + DCC/ED$20+$ DETA compositions on the modifier concentration: $\sigma_{\mathrm{p}}(1), \tau_{\mathrm{B}}$ (2), $\sigma_{\text {p.o }}(3)$, and $\varepsilon_{\mathrm{p}}(4)$. preparation of oligoethercyclocarbonates (OECC) and their use in joint curing with epoxy oligomers. The resulting polymers contain in the network structure additional linear hydroxyurethane fragments. These "relaxators" are capable of manifesting intermolecular interactions that affect the relaxation properties and molecular mobility. The last causes an increase in adhesion and elastic-deformation characteristics and opens additional opportunities in the development of new materials and technologies in the polymer material science.

\section{Data Availability}

The data used to support the findings of this study are available from the corresponding author upon request.

\section{Conflicts of Interest}

The authors declare that they have no conflicts of interest.

\section{Acknowledgments}

The work was carried out within the framework of State Assignment number 10.4763.2017/8.9. The authors would like to thank the companies and employees of KSUAE, KNRTU, and SKZ for the supporting work, which have made a significant contribution to the implementation of these results.

\section{References}

[1] B. Erman and J. E. Mark, Structure and Properties of Rubberlike Networks, Oxford University Press, New York, NY, USA, 1997.

[2] R. F. Stepro, Polymer Networks. Principles of Their Formstion, Structure and Properties, Springer, Luxemburg, Belgium, 1998.

[3] Y. Osada and A. R. Khokhlov, Polymer Gels and Networks, Marcel Dekker, New York, NY, USA, 2002.

[4] A. S. Lipatov, T. T. Alekseeva, L. A. Sorochinskaya, and G. V. Dudarenko, "Confinement effects on the kinetics of formation of sequential semi-interpenetrating polymer networks," Polymer Bulletin, vol. 59, no. 6, pp. 739-747, 2008.

[5] S. Goswami and D. Chakrabarty, "Sequential interpenetrating polymer networks of novolac resin and poly(n-butyl methacrylate)," Journal of Applied Polymer Science, vol. 102, no. 4, pp. 4030-4039, 2006.

[6] M. Patri, C. V. Reddy, C. Narasimhan, and A. B. Samui, "Sequential interpenetrating polymer network based on styrene butadiene rubber and polyalkyl methacrylates," Journal of Applied Polymer Science, vol. 103, no. 2, pp. 1120-1126, 2007.

[7] L. V. Karabanova, L. M. Sergeeva, and A. V. Svyatyna, "Heterogeneity of glass transition dynamics in polyurethanepoly(2-hydroxyethyl methacrylate) semi-interpenetrating polymer networks," Journal of Polymer Science Part B: Polymer Physics, vol. 45, no. 8, pp. 963-975, 2007.

[8] J. F. Fu, L. Y. Shi, S. Yuan, Q. D. Zhong, D. S. Zhang, and Y. Chen, "Morphology, toughness mechanism, and thermal propertiesof hyperbranched epoxy modified diglycidyl ether 
of bisphenol A (DGEBA) interpenetrating polymer networks," Polymers for Advanced Technologies, vol. 19, pp. 1597-1607, 2008.

[9] A. Martinelli, L. Tighzert, L. D’Ilario, I. Francolini, and A. Piozzi, "Poly(vinyl acetate)/polyacrylate semi-interpenetrating polymer networks. II. Thermal, mechanical, and morphological characterization," Journal of Applied Polymer Science, vol. 111, no. 6, pp. 2675-2683, 2009.

[10] V. I. Irzhak and S. M. Mezhikovski, "Kinetics of oligomer curing," Russian Chemical Reviews, vol. 77, no. 1, pp. 77-104, 2008, in Russian.

[11] A. A. Askadski and V. I. Kondrashenko, Computer Material Science of Polymers, Scientific World, Moscow, Russia, 1999, in Russian.

[12] D. W. Van Krevelen and K. T. Nijenhuis, Properties of Polymers, Elsevier, Amsterdam, Netherlands, 2009.

[13] D. R. Wentzel and W. Oppermann, "Orientation relaxation of linear chains enclosed in a network studied by birefringence measurements," Colloid and Polymer Science, vol. 275, no. 3, pp. 205-213, 1997.

[14] I. T. Smith, "The mechanism of the crosslinking of epoxide resins by amines," Polymer, vol. 2, pp. 95-108, 1961.

[15] B. A. Rozenberg, "Epoxy resins and composites II," Advances in Polymer Science, vol. 75, pp. 113-165, 1986.

[16] A. M. Elyashevich, "Computer simulation of network formation processes, structure and mechanical properties of polymer networks," Polymer, vol. 20, no. 11, pp. 1382-1388, 1979.

[17] P. J. Flory, Principles of Polymer Chemistry, Cornell University Press, New York, NY, USA, 1953.

[18] V. M. Lanzov, V. F. Stroganov, and L. A. Abdrahmanova, "Interrelation of kinetic and structural-topological heterogeneity of molecules in polycondensation epoxy-amine network," High-Molecular Compounds, vol. 31, pp. 409-413, 1989, in Russian.

[19] V. I. Irzhak, Architecture of Polymers, in Russian, Science, Moscow, Russia, 2012.

[20] K. Dušek and M. Duškova-Smrckova, "Network structure formation during crosslinking of organic coating systems," Progress in Polymer Science, vol. 25, no. 9, pp. 1215-1260, 2000.

[21] V. I. Irzhak, "Methods of description of the polycondensation kinetics and the structures of the polymers formed," Russian Chemical Reviews, vol. 66, no. 6, pp. 541-552, 1997.

[22] V. Bellenger, J. Verdu, and J. Francillette, "Infra-red study of hydrogen bonding in amine-crosslinked epoxies," Polymer, vol. 28, no. 7, pp. 1079-1086, 1987.

[23] E. Morel, V. Bellenger, and J. Verdu, "Structure-water absorption relationships for amine-cured epoxy resins," Polymer, vol. 26, no. 11, pp. 1719-1724, 1985.

[24] P. J. Bell, "Mechanical properties of a glassy epoxide polymer: effect of molecular weight between crosslinks," Journal of Applied Polymer Science, vol. 14, no. 7, pp. 1901-1906, 1970.

[25] R. E. Cuthrell, "Macrostructure and environment-influenced surface layer in epoxy polymers," Journal of Applied Polymer Science, vol. 11, no. 6, pp. 949-952, 1967.

[26] T. Hirai and D. E. Kline, "Dynamic mechanical properties of nonstoichiometric, amine-cured epoxy resin," Journal of Applied Polymer Science, vol. 16, no. 12, pp. 3145-3157, 1972.

[27] D. M. Brewis, J. Comyn, and J. R. Fowler, "An aliphatic amine cured rubber modified epoxide adhesive: 2 further evaluation," Polymer, vol. 18, no. 9, pp. 951-954, 1977.
[28] J. M. Pochan, R. J. Gruber, and D. F. Pochan, "Dielectric relaxation phenomena in a series of polyhydroxyether copolymers of bisphenol-a engcopped polyethelene glycol with epichlorhydrin," Journal of Polymer Science: Polymer Physics Edition, vol. 19, no. 1, pp. 143-149, 1981.

[29] H. Batzer and S. A. Zahir, "Studies in the molecular weight distribution of epoxide resins. IV. Molecular weight distributions of epoxide resins made from bisphenol A and epichlorohydrin," Journal of Applied Polymer Science, vol. 21, no. 7, pp. 1843-1857, 1977.

[30] V. Besse, F. Camara, C. Voirin, R. Auvergne, S. Caillol, and B. Boutevin, "Synthesis and applications of unsaturated cyclocarbonates," Polym Chem, vol. 4, no. 17, pp. 4545-4561, 2013.

[31] V. F. Stroganov, V. N. Savchenko, and S. I. Omelchenko, Cyclocarbonates and Their Use for the Synthesis of Polymers, Institute of Technical and Economic Research, Moscow, Russia, 1984, in Russian.

[32] A. C. Lind, "An NMR study of inhomogeneities in epoxy resins," American Chemical Society, Division of Polymer Chemistry, vol. 21, pp. 241-242, 1980.

[33] D. W. Larsen and J. H. Strange, "Diglycidyl ether of bisphenol-A with $4,4^{\prime}$-methylenedianiline: a pulsed NMR study of the curing process," Journal of Polymer Science Part A-2: Polymer Physics, vol. 11, no. 7, pp. 1453-1459, 1973.

[34] T. I. Kadurina, V. A. Prokopenko, and S. I. Omelchenko, "Curing of epoxy oligomers by isocyanates," Polymer, vol. 33, no. 18, pp. 3858-3864, 1992.

[35] Z. S. Petrović, Z. Zavargo, J. H. Flyn, and W. J. Macknight, "Thermal degradation of segmented polyurethanes," Journal of Applied Polymer Science, vol. 51, no. 6, pp. 1087-1095, 1994.

[36] A. D. Wicks and Z. W. Wicks, "Blocked isocyanates III: part B: uses and applications of blocked isocyanates," Progress in Organic Coatings, vol. 41, no. 1-3, pp. 1-83, 2001.

[37] J. Guan, Y. Song, Y. Lin et al., "Progress in study of nonisocyanate polyurethane," Industrial and Engineering Chemistry Research, vol. 50, no. 11, pp. 6517-6527, 2011.

[38] W. Zhijun, C. Wang, C. Ronghua, and Q. Jinqing, "Synthesis and properties of ambient-curable non-isocyanate polyurethanes," Progress in Organic Coatings, vol. 119, pp. 116122,2018

[39] M. A. Levina, V. G. Krasheninnikov, and M. V. Zabalov, "Nonisocyanate polyurethanes from amines and cyclic carbonates: kinetics and mechanism of a model reaction," Polymer Science Series B, vol. 56, no. 2, pp. 139-147, 2014.

[40] V. F. Stroganov and I. V. Stroganov, "Peculiarities of structurization and properties of nonisocyanate epoxyurethane polymers," Polymer Science Series C, vol. 49, no. 3, pp. 258263, 2007.

[41] J. Tabushi and R. Oda, "Kinetic study of the reaction of ethylene carbonate and amines," Nippon Kagaki Zasshi, vol. 84, no. 2, pp. 162-167, 1963.

[42] V. F. Stroganov, V. N. Savchenko, and G. D. Tizkij, “Aminolysis of 1-phenoxy-2,3-propylene carbonate benzylamine in chlorobenzene," Journal of Organic Chemistry, vol. 24, pp. 501-504, 1988, in Russian.

[43] Y. Smirnov, B. Komarov, P. Kushch, T. Ponomareva, and V. Lantsov, "Structural and kinetic features of formation of high-strength epoxy-amine cross-linked polymers by combined polycondensation-polymerization process," Russian Journal of Applied Chemistry, vol. 75, no. 2, pp. 265-275, 2002. 
[44] Y. S. Lipatov, "Interfacial regions in the phase-separated interpenetrating networks," Polymer Bulletin, vol. 58, no. 1, pp. 105-118, 2007.

[45] Y. S. Lipatov, R. A. Veselovsky, and Y. K. Znachkov, "Some properties of glues based on interpenetrationg polymeris networks," Journal of Adhesion, vol. 10, no. 2, pp. 157-161, 1979.

[46] V. F. Stroganov, V. M. Mihalchuk, and V. M. Lanzov, "Study of molecular mobility during the curing of diphenylolpropane-1,3-bis (aminomethyl) adamant digymondyl ether system," Russian Academy of Sciences, vol. 291, pp. 908-912, 1986, in Russian.

[47] V. A. Bershtein, N. N. Peschanskaya, J. L. Halary, and L. Monnerie, "The sub-Tg relaxations in pure and antiplasticized model epoxy networks as studied by high resolution creep rate spectroscopy," Polymer, vol. 40, no. 24, pp. 6687-6698, 1999. 


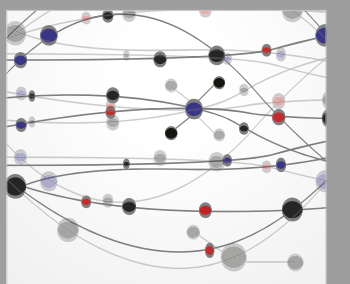

The Scientific World Journal
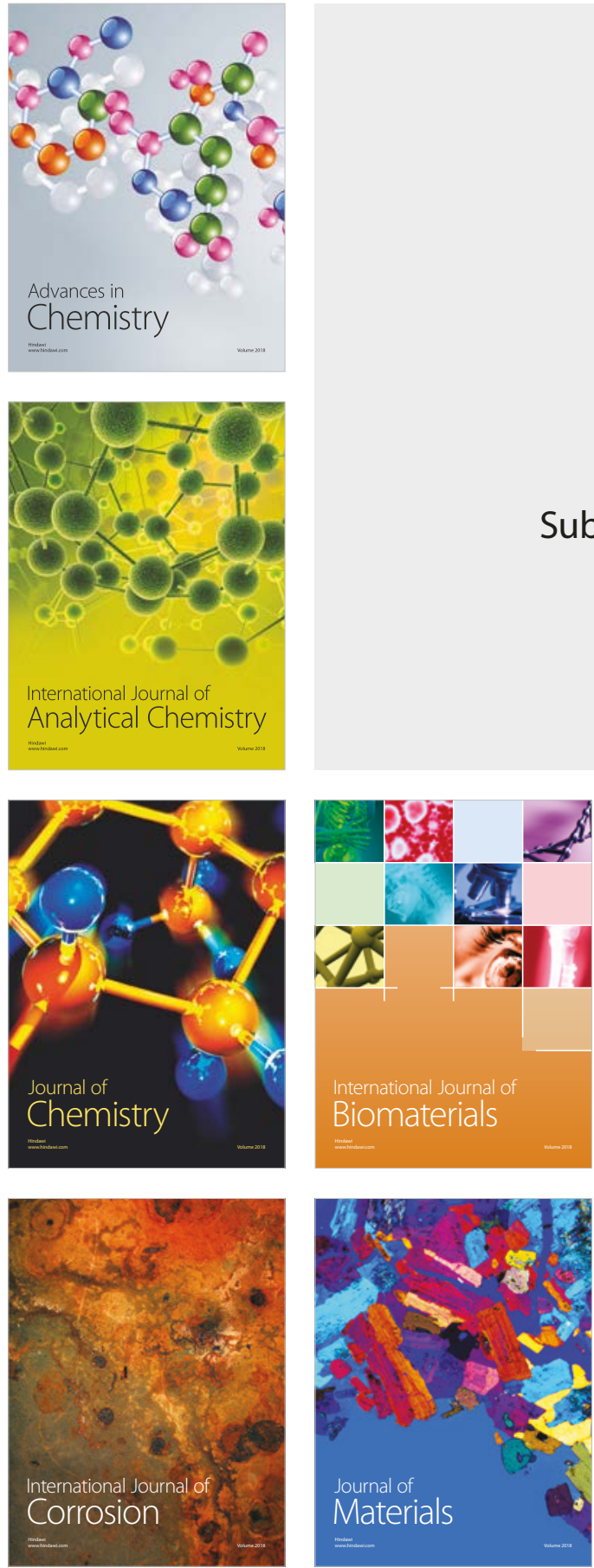

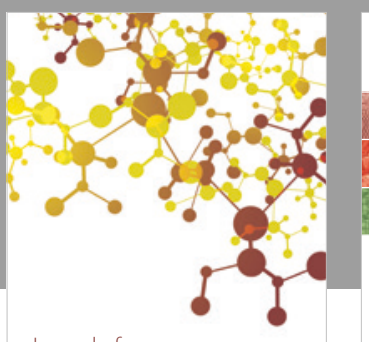

Journal of

Applied Chemistry
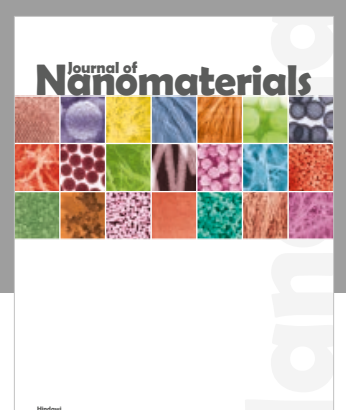

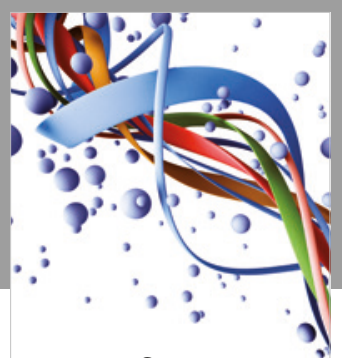

Scientifica

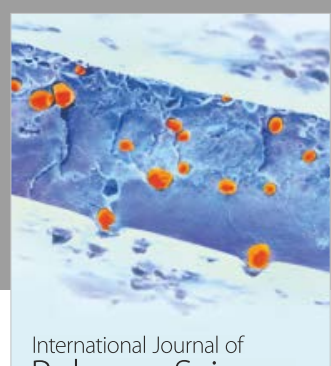

Polymer Science

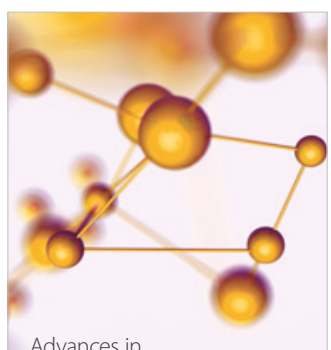

Physical Chemistry
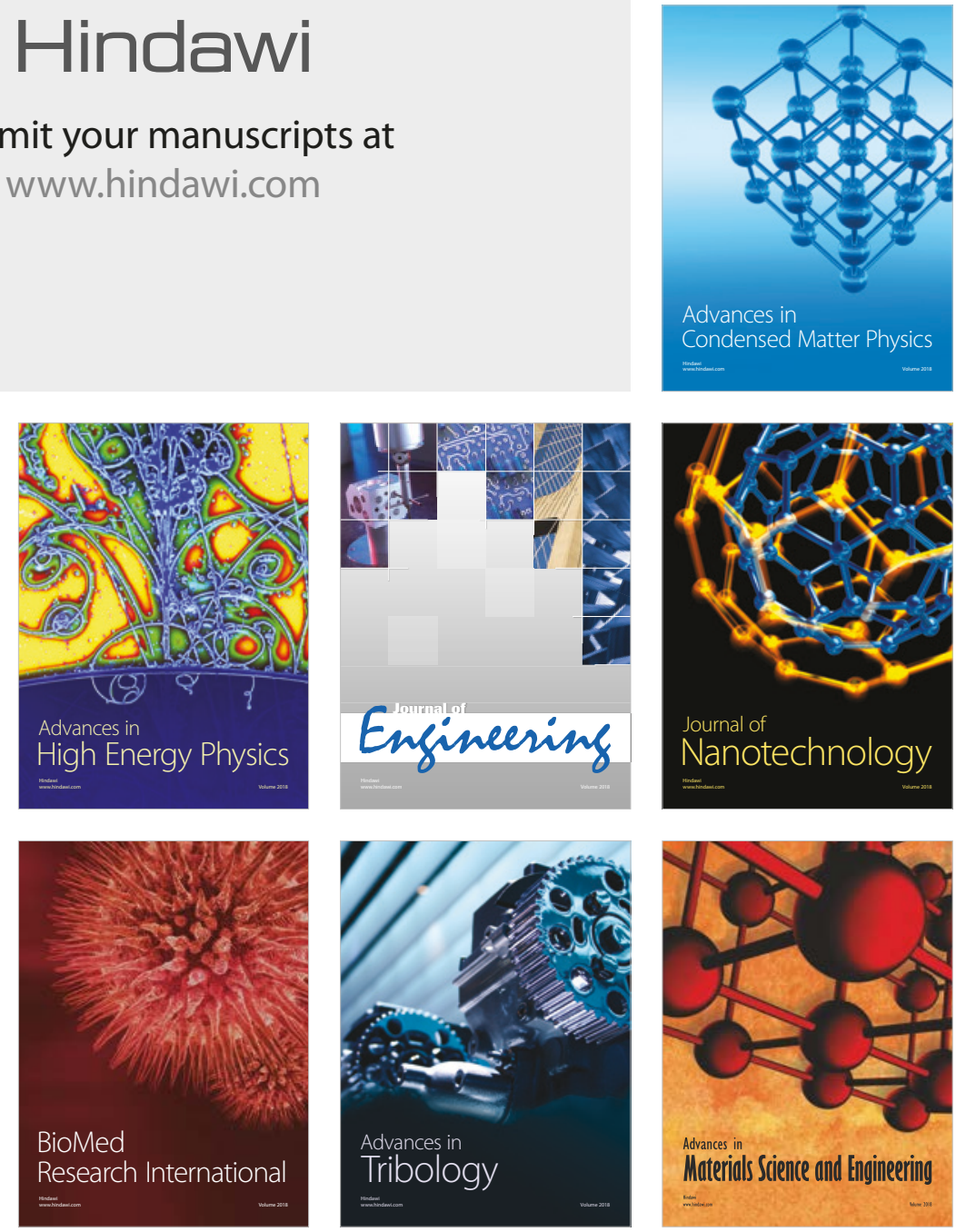